\title{
Missing snowmelt runoff following drought explained by root-zone storage deficits
}

\author{
Dana A Lapides 1,2, W Jesse Hahm², Daniella M Rempe3, David N Dralle ${ }^{1}$ \\ 1 Pacific Southwest Research Station, USDA Forest Service, Davis, CA, USA \\ 2 Department of Geography, Simon Fraser University, Burnaby, BC, Canada \\ 3 University of Texas, Austin, Austin, TX, USA
}

This pre-print is not peer-reviewed. This pre-print will be submitted to PNAS. 


\title{
Missing snowmelt runoff following drought explained by root-zone storage deficits
}

\author{
Dana A Lapides ${ }^{\mathrm{a}, \mathrm{b}, 1}, \mathrm{~W}$ Jesse Hahm ${ }^{\mathrm{b}}$, Daniella M Rempe ${ }^{\mathrm{c}}$, and David N Dralle

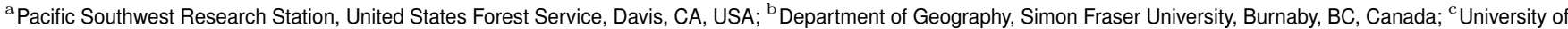 \\ Texas, Austin, Austin, TX, USA \\ This manuscript was compiled on March 4, 2022
}

\begin{abstract}
Water resources management in mountainous regions hinges on forecasting runoff during annual snowmelt periods. However, extreme droughts driven by climate change are altering snowpack-runoff relationships. The current megadrought in the Western United States provides a case in point: in 2021 in California, the historically reliable relationship between April 1 snowpack and runoff failed-much less streamflow arrived than was predicted. Several factors have been proposed to account for this 'missing' streamflow, including: evapotranspiration, rainfall, snowmelt rate, and a dry subsurface. Here, we introduce a model that includes each of these mechanisms and, by applying the model at $\mathbf{1 3}$ basins in the Sierra Nevada, we find that root-zone storage deficits (i.e., the net depletion of plant-accessible water from soil and weathered bedrock via evapotranspiration) lead to the most important snowmelt runoff reductions in years following drought. By accounting for the deficit in a model for snowmelt runoff, overprediction of total 2021 streamflow decreased from $100 \%$ to $12 \%$. Our findings indicate that the relationship between snowpack and runoff in mountain watersheds will evolve as plant ecosystems respond to climate change and alter subsurface water storage dynamics. Through this climatic transition, root-zone storage deficits will play an essential role in snowmelt runoff prediction. Fortunately, deficits can be readily calculated prior to snowmelt using publicly available hydrologic datasets.
\end{abstract}

Sierra Nevada | Forecasting | Water resources | Evapotranspiration | Snowpack

\section{Introduction}

M ountains are considered the water towers of the world $(2,3)$, with mountain snowpack acting as an essential water reservoir for 1.9 billion people globally (4). However, the accessibility of this water depends on how snowmelt runoff is generated. Historically, managers have relied on statistical relationships between snowpack and subsequent runoff for forecasting (5), but changes in climate can alter these relationships. Recently, following a severe drought in California, streamflow forecasts from historically reliable snowpack-runoff relationships (6) far exceeded actual streamflow (see for example, Figure 1a-b). This led scientists and the public alike (e.g., $7,8)$ to wonder - where did the missing snowmelt go?

Previous work has proposed that shifts in streamflow generation from a given water input (snowpack) arise from changes in: (i) evapotranspiration (ET) due to: changes in evaporative demand (9-11), snowmelt rate (12), and/or vegetation community (13-15); or (ii) antecedent conditions (e.g., 10, 16-18), which can be described by prior water inputs or direct observation of subsurface moisture. Both of these factors can be tied to a form of runoff generation in which significant runoff is generated only after infiltrating water replenishes subsurface

storage $(19,20)$, rather than infiltration-excess overland flow (21). During the growing season, moisture is withdrawn from the root-zone primarily through ET, such that by the onset of winter a moisture deficit (see Figure 1d) has accrued in the subsurface (20, 22-33). Infiltrating water goes first to replenishing this moisture deficit and then towards generating streamflow. Less water input prior to snowmelt (i.e., winter rainfall) or more evapotranspiration can limit how quickly the storage deficit is replenished - the precondition for significant streamflow generation. In this way, subsurface moisture conditions interact with above-ground factors to mediate runoff generation from snowpack.

While there are distributed datasets for precipitation and ET, subsurface moisture conditions remain difficult to quantify at large spatial scales. Deficits in the root zone occur in both soils and underlying weathered bedrock, which can account for a large portion of root-zone water storage $(23,30,34,35)$. Although soil moisture data are broadly available, storage in weathered bedrock is less easy to monitor. There are currently no real-time, widespread monitoring systems for bedrock water storage. Storage changes recorded by GRACE (36) are not finely resolved and include water storage effects (e.g., deep groundwater) that may not be relevant to the rootzone, and modeled subsurface water storage is contingent on the reliability of model parameterization, which is typically limited to soils, not bedrock.

Given that the root-zone storage deficit emerges from the

\section{Significance Statement}

More frequent droughts and increasing temperatures imposed by climate change threaten snowpacks, which sustain mountain water resources globally. Following a recent drought in California, the traditionally used model for snowmelt runoff failed. Here, we present a model that reveals the essential role of root-zone storage dynamics in snowmelt runoff. Through transpiration, montane forests generate water storage deficits in the soils and weathered bedrock that comprise the root zone. These deficits must be replenished by rain and snowmelt before significant runoff generation can occur. Overprediction of 2021 post-drought runoff in California can be primarily attributed to unprecedented root-zone storage deficit magnitudes. Adding a measure of deficit reduced 2021 streamflow prediction error from $100 \%$ to $12 \%$.

DND conceived of the study. DAL and DND formulated the hydrological model. DAL compiled data conducted analyses, generated graphics, and wrote the initial manuscript. W.JH and DND reviewed analysis code. All authors were involved in idea generation, significant manuscript revision, and review of the final manuscript.

The authors have no conflicts of interest to declare.

${ }^{1}$ To whom correspondence should be addressed. E-mail: dlapides@sfu.ca 

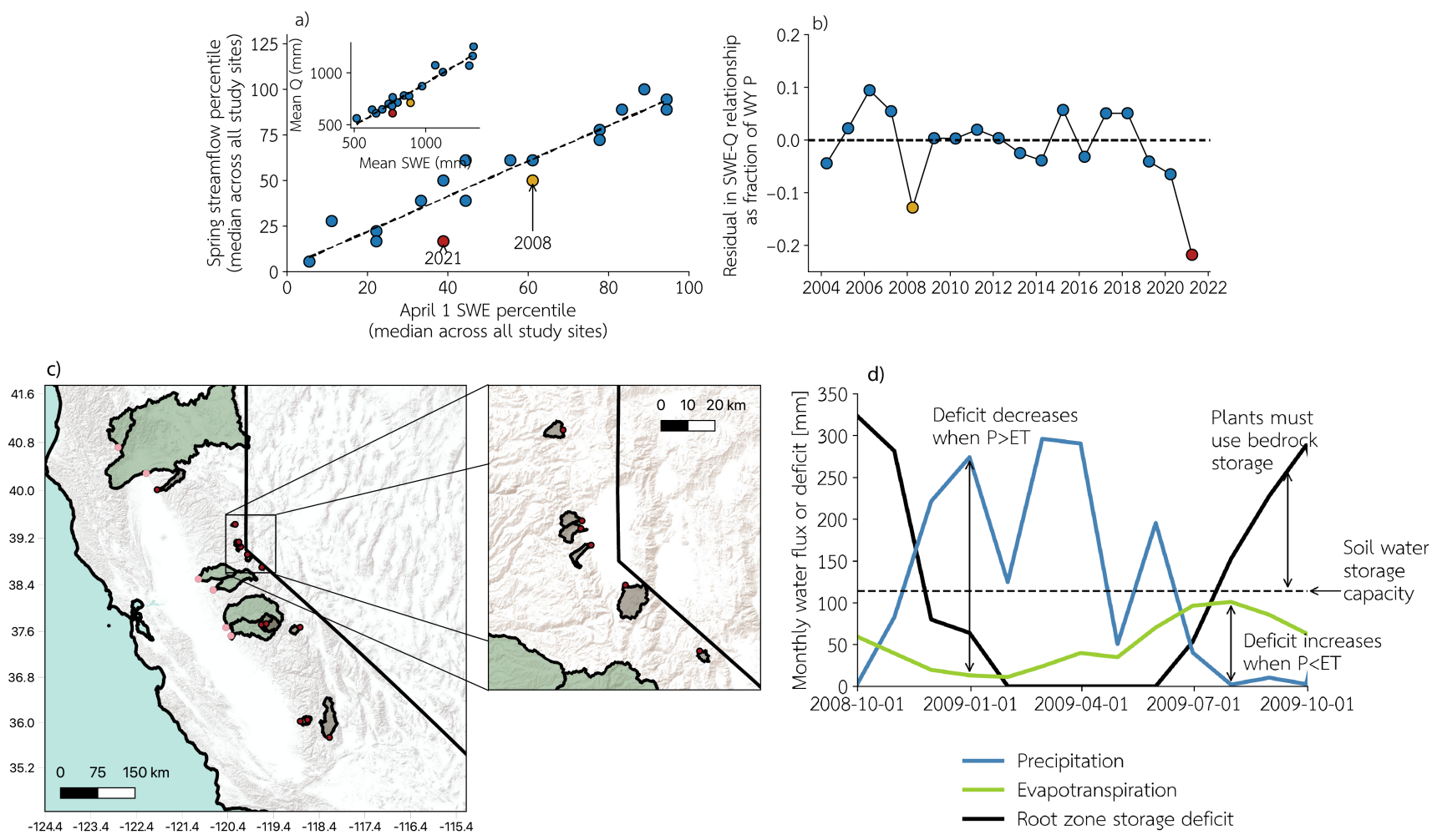

Fig. 1. (a) Linear relationship between April 1 snow water equivalent (SWE) and spring (April-July) streamflow summarized at 13 study sites as the relationship between median April 1 SWE percentile and median spring streamflow percentile for each year within the study period (2003-2021). This regression model is of a similar form to the one used by the California Department of Water Resources to produce streamflow forecasts. Inset shows the same plot for the mean value of April 1 SWE and spring streamflow among the 13 study sites. Points that fall above the dashed line are years where the linear model under-predicts streamflow, and points that lie below the line are years where the linear model over-predicts streamflow. 2021 and 2008 are highlighted as particularly large negative residuals. SWE data is from SNODAS (1). (b) Median residual in the SWE-spring streamflow relationship among the 13 study sites as a fraction of April 1 SWE. (c) Map of study watersheds in the Sierra Nevada. Red dots mark gage locations at watershed outlets for pristine sites shaded in grey, and pink dots for basins important for water supply shaded in green. (d) Explanatory plot for root zone storage deficit for one water year. At the beginning of the wet season, the deficit decreases (storage fills up) until storage plateaus at a maximum value, after which the deficit remains 0 until ET exceeds $\mathrm{P}$ again in the dry season, and the deficit grows until the beginning of the next wet season. When deficit exceeds the soil water storage capacity, this indicates that plants have accessed water stored below soil in weathered bedrock.

balance between incoming and outgoing water fluxes, changes in the deficit can be inferred using flux timeseries. Spatially distributed, running, near real-time plant-driven water storage dynamics throughout both soil and bedrock can thus be quantified from precipitation and ET timeseries (37-39). Considering storage deficits in runoff prediction (40) or as a harbinger of drought $(41,42)$ is not new, but the widespread availability of ET and precipitation datasets (37), snow cover data (38), and distributed snow water equivalent (SWE) now allows for widespread monitoring of deficits in mountainous regions.

Here, we seek to understand how subsurface water storage dynamics - in combination with other previously studied mechanisms - inform forecasting of snowmelt runoff by exploring the fate of the 'missing' 2021 snowmelt runoff in California.

\section{Conceptual model for runoff generation in mountainous regions}

We introduce a mass-balance model for snowmelt driven runoff in a Mediterranean environment (wet winter, dry growing season) that explicitly incorporates the root-zone water storage deficit to explore the following potential explanations for runoff reduction:

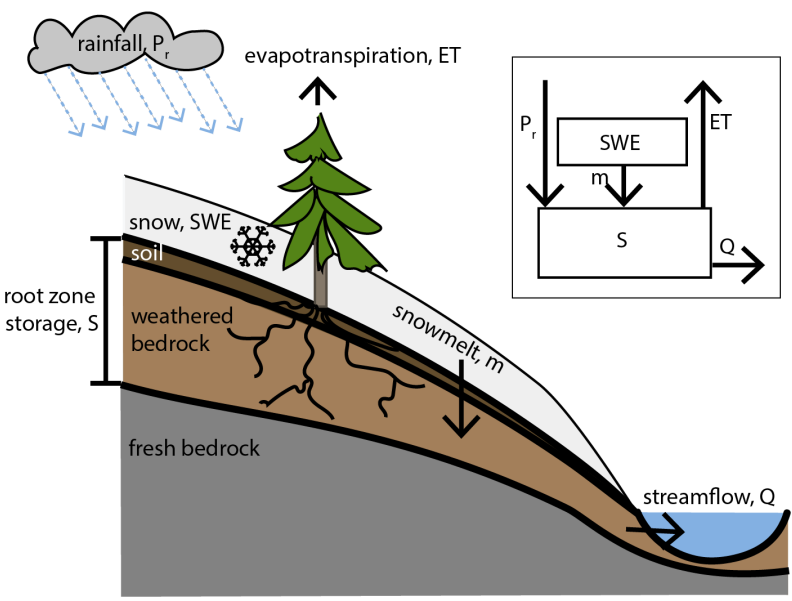

Fig. 2. Conceptual hillslope diagram of mountain hydrology. Thin soils cover a deep, weathered bedrock zone that plants access throughout the dry season. Snow accumulates during the winter and melts into the subsurface, while rain directly replenishes the subsurface. Evapotranspiration reduces water in storage, and streamflow is generated once a subsurface storage deficit is replenished. The inset diagram shows the two modeled water reservoirs (snow and root zone storage) and fluxes (rainfall, snowmelt, evapotranspiration, and streamflow). 
1. Less rainfall fell than usual during the winter or spring

2. Snowmelt rate was slower than usual

3. Evaporative demand was higher than usual during the winter

4. Evaporative demand was higher than usual during the spring

5. The root-zone water storage deficit at the start of the wet season was larger than usual.

In the model, the subsurface is treated as a single root-zone storage reservoir that represents conceptually a thin soil layer underlain by deep weathered bedrock (Figure 2), as is common in forested mountainous environments $(30,43-45)$. The model does not specify where water is stored within the subsurface or its energy state (e.g., saturated versus unsaturated). Fluxes act on the storage reservoir through three hydrological seasons: a winter wet season when rain enters storage and snow accumulates, a snowmelt season when rain and snowmelt enter storage, and a dry summer season. ET draws from storage at different rates in each season. Starting at the beginning of the wet season, there is a deficit generated by the previous dry season that shrinks with water input during the winter wet season and snowmelt periods (Figure 1d). Once the deficit is reduced to 0, streamflow is generated (such as in the 'fill and spill' mechanism or observed delays in wet season runoff; 19, 20). As ET begins to exceed snowmelt and rain in the spring, streamflow stops, and the deficit grows again until the start of the next wet season. Snowmelt runoff emerges as the net melt season water input (snowmelt and precipitation less ET) once the deficit has been met. Within the resulting expression, each of the hypotheses suggested above appear as variables. See Supplemental Information S2 for more details on the mass balance model. We validate our mass balance model against observed spring streamflow at 13 pristine sites in the Sierra Nevada (see Supplemental Information S1 for details on site selection and Supplemental Information S8 for additional analyses on 6 basins essential to California's water supply), and then develop a multiple linear regression model to quantify which drivers have the largest impact on snowmelt runoff.

\section{Observations validate a conceptual model for snowmelt runoff based on root zone storage dynamics}

The mass balance model of root zone storage (Equation 1) accurately predicts measured spring streamflow $\left(R^{2}=0.84\right.$ for one-to-one line, see Figure $3 \mathrm{a}$ ) at 13 sites in the Sierra Nevada (grey sites in Figure 1c). Panels b-e plot these same predictions in parameter space (compare scatter color to background). Good model performance despite a lack of tunable parameters suggests that the primary mechanisms for spring streamflow generation at the study sites are accounted for in our conceptual framework.

\section{Root zone storage deficit is important for determining runoff efficiency}

We regressed spring runoff (April-July, proxy for snowmelt runoff) on the variables identified in the storage-based modeling framework (Equation 2) to compute typical effect sizes
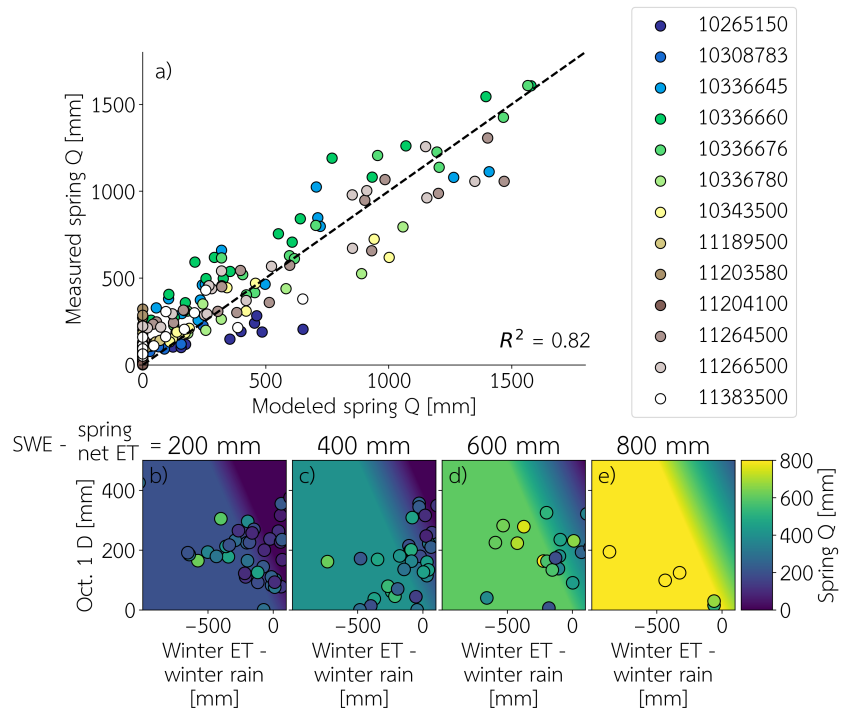

Fig. 3. (a) Comparison between measured spring streamflow at each study site and predicted streamflow based on Equation 1. Legend refers to USGS streamgauge ID. (b-e) Heatmaps showing how modeled streamflow varies based on each model parameter. Within each panel: winter ET - winter rain increases moving right, and October 1 deficit increases vertically. Moving to the right between panels, April $1 \mathrm{SWE}$ - (spring ET - spring rain) increases. Points plotted on heatmaps represent a single water year for a study site and are colored by measured spring streamflow. Points are plotted on the heatmaps if $S W E-E T_{n e t} N_{\text {melt }}$ is within $100 \mathrm{~mm}$ of the value labeled for each panel.

for each forcing variable. This allowed us to quantitatively rank the importance of different physical drivers of snowmelt runoff generation during years following both wet (above 75 th percentile of annual precipitation) and dry (below 25th percentile of annual precipitation) years in Figure 4. Variables are described for the water balance feature they represent, but actual variables (except SWE) are normalized by WY P or, in the case of melt rate, net spring ET. In both wet and dry years, rainfall has the largest impact on model outcomes (after snowpack), but in dry years, a shift in the dominant hydrological processes makes the deficit nearly as important as rainfall. See Supplemental Tables 3 and 4 for effect sizes for all variables at all sites on wet and dry years. Besides a few exceptions for individual basins, the sign for each effect size matches the expected sign based on hypothesized model mechanisms at all sites (see Supplemental Table 3), providing further evidence for the proposed mechanisms. No more than one site shows an unexpected sign for any parameter except for the melt rate, which has an unexpected sign at 4 sites. Given the melt rate's low effect sizes and unexpected effect signs, we conclude melt rate is relatively insignificant in comparison to other explanatory variables. The median $\mathrm{R}^{2}$ value for multiple linear regression models across the study sites is 0.93 .

A linear model may not account for complex interactions between the hydrologic processes used in the regression. Thus, we also trained a single random forest model to predict spring streamflow at all sites based on the same set of input parameters (model performance $R^{2}=0.98$ ). Results from the random forest analysis also support the hypothesized mechanisms, and contribution of parameters to model outputs as measured by feature importance confirms that October 1 deficit and spring net ET are important drivers of snowmelt runoff, whereas the melt rate is less important. See Supplemental Information S6 


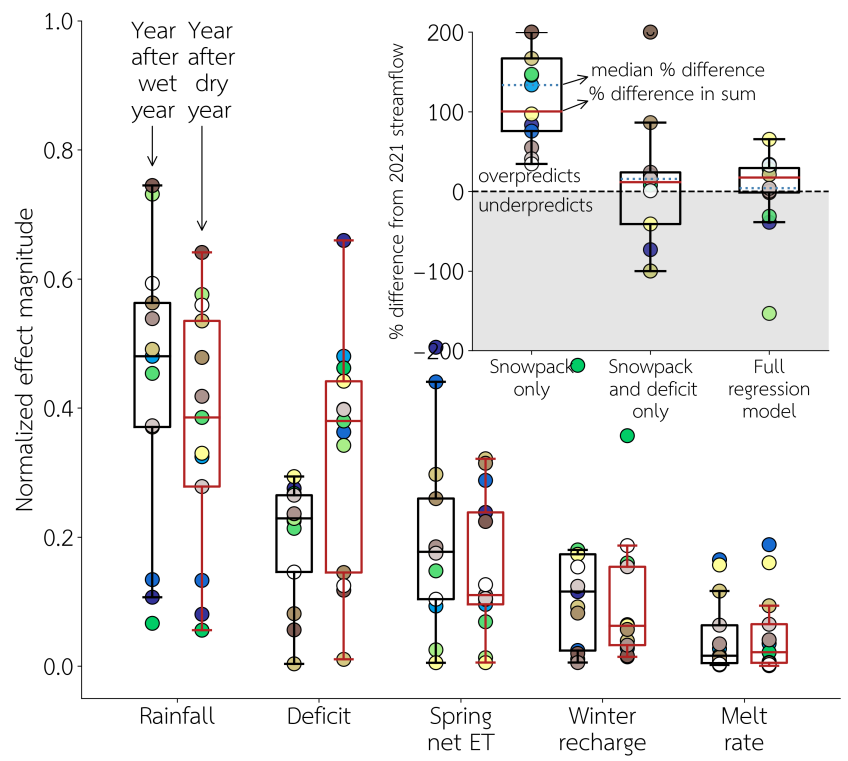

Fig. 4. Normalized effect magnitude of each variable included in the multiple linear regression for snowmelt runoff at all sites, comparing the set of years following wet years to years following dry years during the study period. Snowpack is excluded from this plot but is generally the most important variable. Variable names are described for the water balance feature they represent, but rainfall, deficit, spring net ET, and winter recharge are relative to water year precipitation in the model to reduce correlation among variables, and melt rate is relative to spring net ET. Box and whisker plot shows median value across all sites. Effect size is the coefficient for a given variable multiplied by the median absolute value of the variable for years following wet (black) or dry (red) years. Normalization is achieved by scaling the effect sizes for each site so that their absolute values sum to 1 , and the magnitude of these normalized values is reported. The inset plot shows performance of regression models at 13 study sites for the year 2021. A linear regression model using only April 1 SWE overpredicts the total 2021 spring streamflow at all sites by $100 \%$ (median 134\%), while the full linear regression model or a model using April 1 SWE and October deficit as a fraction of winter precipitation overpredicts the total by 17 or $12 \%$ (median of 15 or $4 \%$ ) respectively. Legend is the same as for Figure 3.

for more details.

A linear regression model using only snowpack (Figure 1a), similar to the regression model currently used to predicted snowmelt runoff in California (46), replicates the 2021 "missing" streamflow phenomenon with a similar magnitude of error in 2021 (6). By adding a term representing the deficit (linear regression using only snowpack and deficit), model performance improves to a median of $R^{2}=0.85$, a median improvement of 0.05 over a model using only snowpack. For site-specific details, see Supplemental Table 3.

While the improvements in $R^{2}$ may appear modest, the more complex linear regression models perform significantly better at capturing streamflow on anomalous years (See Supplemental Information Figure S4 for details on improved model performance on a year with underprediction). The inset in Figure 4 shows predictions for 2021 streamflow at all sites using the full multiple linear regression model, snowpack and deficit only, and snowpack only. Each regression model is trained on data from the full study period. Using only snowpack, the model over-predicts the 2021 total streamflow from all sites by $100 \%$. Using the full regression model, total streamflow is only over-predicted by $17 \%$, and with snowpack and deficit it is over-predicted by only $12 \%$. For each site, the median overprediction using a regression model with only snowpack is $134 \%$, with the full regression model $4 \%$, and with snowpack and deficit $15 \%$.

\section{Discussion and conclusions}

We fit a multiple linear regression model based on a validated conceptual framework to rank the impact of different hydrological drivers on snowmelt runoff. Our findings indicate that the phenomenon of "missing" streamflow in the 2021 water year is primarily attributable to an unusually large root zone storage deficit at the start of the wet season. Adding a term to describe root zone storage deficit decreased total overprediction of 2021 snowmelt runoff in a linear regression model from a $100 \%$ to $12 \%$, an essential improvement for water resources management. Among the terms indicated to be most important by effect size in the multiple linear regression model, only the October 1 deficit is knowable prior to the snowmelt season and therefore potentially available for forecasting.

In some sense, the result that the deficit is important is not surprising since managers and researchers have long recognized the qualitative importance of subsurface moisture conditions for subsequent runoff (e.g., personal communication with Sean de Guzman, chief of the California Department of Water Resources Snow Surveys and Water Supply Forecasting Section, and 20, 22-33, 40). However, incorporating root zone dynamics into models remains challenging due to data limitations on water storage in weathered bedrock. Despite great community interest, the task of operationalizing (or even quantifying the importance of) the deficit remains formidable. The presented model quantitatively captures the expected importance of subsurface moisture conditions for runoff forecasting, providing a possible solution to the problem of unreliable runoff prediction that requires minimal inputs and few assumptions $(37,38)$. The framework is especially useful following dry years, when the impact of the deficit on snowmelt runoff production is increased. Methods that can account for deep drying in the root zone following drought will be essential under increasingly volatile and extreme future climate scenarios (47). A further implication of our findings that the deficit is key to forecasting water supply is that most runoff generation must be primarily through the subsurface, as suggested in our conceptual model, rather than through infiltration-excess overland flow, which should be minimally sensitive to subsurface moisture conditions.

We selected a set of basins that were minimally disturbed to test our model. However, given that the deficit is calculated using remotely-sensed evapotranspiration, it should be sensitive to spatial variation in land-cover or forms of disturbance, such as fire, that are known to impact patterns of plant water use (48-51). This suggests our model may be applicable to larger and more complex basins. We therefore also applied the model to six watersheds central to California's water supply (see green basins in Figure 1c and Supplemental Information $\mathrm{S} 1$ for additional site information). As shown in Figure S5, adding a term to a linear regression model to represent the deficit improves error in prediction of 2021 streamflow from a median of $143 \%$ error to $2 \%$ error.

Development of reliable, large-scale ET and P datasets is needed to improve representation of root zone storage deficits in models and predictive frameworks. Beyond streamflow forecasting, deficit approaches are relevant to prediction of ecosystem drought vulnerability (52-54), groundwater quality (55), and carbon cycling (56). As disparate research commu- 
nities coalesce around a need to simulate root zone storage deficits and associated bedrock storage, the conceptual framework presented in this study provides a roadmap for extending our models and considering how changing patterns in deficits may impact our predictions.

\section{Materials and methods}

\section{Table 1. Table of notation.}

\begin{tabular}{lll} 
Variable & Dimensions & Description \\
\hline$Q$ & $\mathrm{~L}$ & Total runoff during snowmelt period \\
$S W E$ & $\mathrm{~L}$ & Snowpack at start of snowmelt period \\
$P$ & $\mathrm{~L}$ & Water year total precipitation \\
$m$ & $\mathrm{~L} / \mathrm{T}$ & Snowmelt rate \\
$E T_{w}$ & $\mathrm{~L}$ & Total winter ET \\
$P_{w}$ & $\mathrm{~L}$ & Total winter rainfall \\
$E T_{n e t}$ & $\mathrm{~L} / \mathrm{T}$ & Spring ET rate - spring rainfall rate \\
$N_{\text {melt }}$ & $\mathrm{T}$ & Length of snowmelt period \\
$D_{\text {oct } 1}$ & $\mathrm{~L}$ & Deficit at start of wet season
\end{tabular}

Mass-balance snowmelt runoff model. Here we expand upon a stochastic hydrological model (52) that incorporates storage as a simple 1-d bucket to describe annual runoff dynamics and plant water availability in Mediterranean catchments. In the original model, precipitation $P[\mathrm{~L}]$ contributes water to storage during the wet season, and evapotranspiration $E T$ [L] removes water from storage primarily during the dry season. Streamflow is generated only if the subsurface storage reservoir is full.

The expanded model consists of three different seasons, as described above in the 'Conceptual model for runoff generation in mountainous regions' section. By tracking a mass balance through these seasons, we derived an expression for streamflow during the snowmelt period $(Q[\mathrm{~L}])$ :

$$
Q=\left\{\begin{array}{l}
\text { if } P_{w}-E T_{w}>D \text { Oct } 1: \\
\max \left(0, S W E-E T_{\text {net }} N_{\text {melt }}\right) \\
\text { otherwise: } \\
\quad \max \left(0, S W E-E T_{\text {net }} N_{\text {melt }}-\right. \\
\left.\quad D_{\text {Oct } 1}+\left(P_{w}-E T_{w}\right)\right)
\end{array}\right.
$$

Notation is defined in Table 1. Both conditions are bounded by zero since streamflow cannot be negative. A negative value for either condition indicates that water demand from ET exceeds water availability from rain and snowmelt, so streamflow must be zero. In Equation 1, all of the mechanisms proposed for missing snowmelt appear: ET appears in $E T_{n e t}$ and $E T_{w}$, rain appears in $E T_{n e t}$ and $P_{w}$, snowmelt rate appears in $N_{\text {melt }}=S W E / m$, and the deficit appears as $D_{\text {Oct } 1}$. For a full description of the model, see Supplemental Information S2 and S3.

A regression model for snowmelt-driven runoff. We performed exploratory data analysis to determine which mechanisms listed in the 'Conceptual model for runoff generation in mountainous regions' section best explain snowmelt runoff at the study sites (shaded in grey in Figure 1c). See Supplemental Information S1 for details on study sites and site selection criteria, and Supplemental Information S5 for additional details on exploratory analysis. To determine which mechanisms have the most explanatory power for deviations from the snowpackrunoff relationship, we developed a multiple linear regression equation at each study site:

$$
\begin{aligned}
Q=C_{1} S W E+C_{2} \frac{D_{\text {Oct } 1}}{P}+C_{3} \frac{E T_{\text {net }} N_{\text {melt }}}{P}+ \\
C_{4} \frac{E T_{w}-P_{w}}{P}+C_{5} \frac{P_{w}+P_{s}}{P}+C_{6} \frac{m}{E T_{\text {net }}}+C_{7},
\end{aligned}
$$

where $C_{1}, \ldots, C_{7}$ are fitted parameters.

Each variable other than SWE is expressed as a fraction of water year precipitation (except for $m / E T_{n e t}$ ). This has the effect of minimizing correlation between variables since many model variables are correlated with water year $\mathrm{P}$. In Equation 2, $E T_{n e t} N_{\text {melt }} / P$ and $\left(E T_{w}-P_{w}\right) / P$ capture effects of variable ET (Hypotheses 3 and 4 in the conceptual runoff model section $),\left(P_{w}+P_{s}\right) / P$ captures effects of variable rainfall (Hypothesis 1$), m / E T_{\text {net }}$ captures effects of variable snowmelt rate (Hypothesis 2 ), and $D_{O c t 1} / P$ captures effects of variable root zone storage deficit (Hypothesis 4 ). We also used a random forest model to corroborate the findings of this regression approach; see Supplemental Information S6 for additional details.

Data sources and data processing. Streamflow data were obtained from the National Water Information System (NWIS, 57) using the package hydrofunctions (https://hydrofunctions. readthedocs.io/en/master/). Daily snow water equivalent was obtained using SNODAS (1). Precipitation data were obtained from PRISM (58). Evapotranspiration and temperature data were obtained from PML V2 (59-61) and MODIS (62) PRISM, MODIS, and PML V2 were accessed via the Google Earth Engine Python API (63). Evaporative stress index (ESI) data were obtained from ClimateServ (64-67). ESI provides a measure of ET anomalies over time using thermal satellite imagery. A higher ESI indicates a larger positive ET anomaly, whereas lower or negative values indicate depressed ET. For comparison with root zone storage deficit, we included soil water storage capacity (68) as processed by McCormick et al. (30).

For the majority of the study period, we use the PML V2 data set for ET. This data set, when combined with PRISM, captures subsurface storage deficits consistent with field measurements (30). Since PML V2 is not yet available through the 2021 water year, we extended the PML V2 data set using MODIS ET. We bias-corrected MODIS ET to PML V2 using a basin-specific linear relationship for each study watershed. For most watersheds, the correlation between PML V2 and MODIS ET is strong (median $\mathrm{R}^{2}>0.4$, see Supplementary Code (69)).

Snowmelt rate was calculated from daily SNODAS data as in Barnhart et al. (12):

$$
m=\frac{\Sigma\left|\min \left(\Delta S W E_{t}, 0\right)\right|}{\Sigma \Delta_{t}}
$$

where the numerator is the sum of all daily differences in SWE on days when SWE decreases, and $\Delta_{t}$ is 1 on days when SWE decreases and otherwise 0 .

The root zone storage deficit was calculated following WangErlandsson et al. (37) and Dralle et al. (38). The only difference here is that instead of using only precipitation and evapotranspiration (37) or approximating information about 
snow using snow cover (38), we used SNODAS data directly to represent accumulation and melt of snowpack. For a full description of deficit calculations, see Supplemental Information S3.

ACKNOWLEDGMENTS. We would like to thank Sean de Guzman, chief of the California Department of Water Resources Snow Surveys and Water Supply Forecasting Section, for providing insight into how runoff is forecast in California. Funding was provided by Simon Fraser University, a Natural Science Engineering Research Council of Canada Discovery Grant, the US National Science Foundationsupported Eel River Critical Zone Observatory (EAR 1331940), and the USDA Forest Service Pacific Southwest Research Station with funds administered by Oak Ridge Institute for Science and Education (ORISE).

\section{Open research}

Data and code generated for this publication are available in an online data repository (69, https://github.com/lapidesd/CA_missing_freshet, ). Raster maps of percentiles of April 1 SWE are available at https: //www.hydroshare.org/resource/4b940b8593a4416e954a47bbbc58c568/ (70). Primary analyses are available as Google Colab notebooks: (i) exploration of relationship between April $1 \mathrm{SWE}$ and spring runoff at each study site (https://colab.research.google.com/drive/ 1tv8kble9EY3vFdAQzbJTfE7RmDpM9uQG?usp=sharing), (ii) calculation of all quantities used in analysis and exploring the four hypotheses stated at the end of the introduction (https://colab.research.google. com/drive/1hq-qqllR_LuEyZ5s5RPddnqDLBo4M309?usp=sharing), (iii) development of a random forest model and a multiple linear regression model for spring streamflow and examines the results (https://colab.research.google.com/drive/ 1jPtdcESsGPfB2H6MC-W7metpiFSqe799?usp=sharing), (iv) implementation of the model described in Section (https://colab.research.google. com/drive/197Hglpe3kkThdbISFz-9U9h63lvdQzE9?usp=sharing, and (v) exploring predictive improvement by adding the deficit at 6 economically import watersheds in California (https://colab.research.google. com/drive/1_igz4g_mbTntAkPZv3SJGwnYIRUEEBFE?usp=sharing).

1. National Operational Hydrologic Remote Sensing Center. Snow data assimilation system (snodas) data products at nsidc, version 1, 2000.

2. Daniel Viviroli, Hans H Dürr, Bruno Messerli, Michel Meybeck, and Rolf Weingartner. Mountains of the world, water towers for humanity: Typology, mapping, and global significance. Water resources research, 43(7), 2007.

3. Walter W Immerzeel, Ludovicus PH Van Beek, and Marc FP Bierkens. Climate change will affect the asian water towers. science, 328(5984):1382-1385, 2010.

4. Walter W Immerzeel, AF Lutz, M Andrade, A Bahl, H Biemans, Tobias Bolch, S Hyde, S Brumby, BJ Davies, AC Elmore, et al. Importance and vulnerability of the world's water towers. Nature 577(7790):364-369, 2020

5. David R DeWalle and Albert Rango. Principles of snow hydrology. Cambridge University Press, 2008.

6. California Department of Water Resources. Dwr bulletin-120 forecast performance, water year 2021, 2021. accessed at https://tableau.cnra.ca.gov/t/DWR_Snow WSFcast/views/WY2021Performance/Dashboard1 ?\%3Adisplay_count=n\&\%3Aembed=y\& \%3AisGuestRedirectFromVizportal=y\&\%3Aorigin=viz_share_link\&\%3AshowAppBanner= false\&\%3AshowVizHome=n.

7. Gabrielle Canon. 'truly an emergency': how drought returned to california - and what lies ahead. Guardian, 2021. accessed at https://www.theguardian.com/us-news/2021/jun/07/ california-drought-oregon-west-climate-change.

8. Paul Rogers. Where did sierra snow go this spring? not into California rivers and water supplies. The Mercury News, 2021.

9. Alan F Hamlet, Philip W Mote, Martyn P Clark, and Dennis P Lettenmaier. Twentieth-century trends in runoff, evapotranspiration, and soil moisture in the western united states. Journal of Climate, 20(8):1468-1486, 2007.

10. Francesco Avanzi, Joseph Rungee, Tessa Maurer, Roger Bales, Qin Ma, Steven Glase and Martha Conklin. Climate elasticity of evapotranspiration shifts the water balance of mediterranean climates during multi-year droughts. Hydrology and Earth System Sciences, 24(9):4317-4337, 2020.

11. Martin Hoerling and Jon Eischeid. Past peak water in the southwest. Southwest Hydrology, 6 (1):18-19, 2007

12. Theodore B Barnhart, Noah P Molotch, Ben Livneh, Adrian A Harpold, John F Knowles, and Dominik Schneider. Snowmelt rate dictates streamflow. Geophysical Research Letters, 43 (15):8006-8016, 2016.

13. Sarah Boon. Snow ablation energy balance in a dead forest stand. Hydrological Processes: An International Journal, 23(18):2600-2610, 2009.

14. Evan Pugh and Eric Small. The impact of pine beetle infestation on snow accumulation and melt in the headwaters of the colorado river. Ecohydrology, 5(4):467-477, 2012.
15. Dennis H Knight, Joseph B Yavitt, and Gregory D Joyce. Water and nitrogen outflow from odgepole pine forest after two levels of tree mortality. Forest Ecology and Management, 46 (3-4):215-225, 1991

16. TW Hawkins and AW Ellis. The dependence of streamflow on antecedent subsurface moisture in an arid climate. Journal of arid environments, 74(1):75-86, 2010.

17. Daniele Penna, HJ Tromp-van Meerveld, Alberto Gobbi, Marco Borga, and Giancarlo Dalla Fontana. The influence of soil moisture on threshold runoff generation processes in an alpine headwater catchment. Hydrology and Earth System Sciences, 15(3):689-702, 2011.

18. Daniele Penna, HILDA JACOBA van Meerveld, Omar Oliviero, Giulia Zuecco, RS Assendelft, Giancarlo Dalla Fontana, and MARCO Borga. Seasonal changes in runoff generation in a small forested mountain catchment. Hydrological Processes, 29(8):2027-2042, 2015.

19. Jeffrey J McDonnell, Christopher Spence, Daniel J Karran, HJ llja van Meerveld, and Ciaran Harman. Fill-and-spill: A process description of runoff generation at the scale of the beholder. Water Resources Research, page e2020WR027514, 2021.

20. Takahiro Sayama, Jeffrey J McDonnell, Amod Dhakal, and Kate Sullivan. How much water can a watershed store? Hydrological Processes, 25(25):3899-3908, 2011.

21. Robert $\mathrm{E}$ Horton. The role of infiltration in the hydrologic cycle. Eos, Transactions American Geophysical Union, 14(1):446-460, 1933.

22. Rodney $\mathrm{J}$ Arkley. Soil moisture use by mixed conifer forest in a summer-dry climate. Soil Science Society of America Journal, 45(2):423-427, 1981.

23. Roger C Bales, Jan W Hopmans, Anthony T O'Geen, Matthew Meadows, Peter C Hartsough, Peter Kirchner, Carolyn T Hunsaker, and Dylan Beaudette. Soil moisture response to snowmelt and rainfall in a sierra nevada mixed-conifer forest. Vadose Zone Journal, 10(3):786-799, 2011.

24. MA Anderson, RC Graham, GJ Alyanakian, and DZ Martynn. Late summer water status of soils and weathered bedrock in a giant sequoia grove. Soil Science, 160(6):415-422, 1995.

25. DP Jones and RC Graham. Water-holding characteristics of weathered granitic rock in chaparral and forest ecosystems. Soil Science Society of America Journal, 57(1):256-261, 1993.

26. DC Lewis and Robert H Burgy. The relationship between oak tree roots and groundwater in fractured rock as determined by tritium tracing. Journal of Geophysical Research, 69(12): 2579-2588, 1964.

27. Gretchen R Miller, Xingyuan Chen, Yoram Rubin, Siyan Ma, and Dennis D Baldocchi. Groundwater uptake by woody vegetation in a semiarid oak savanna. Water Resources Research, 46 (10), 2010.

28. K Rose, R Graham, and D Parker. Water source utilization by pinus jeffreyi and arctostaphylos patula on thin soils over bedrock. Oecologia, 134(1):46-54, 2003.

29. Daniella M Rempe and William E Dietrich. Direct observations of rock moisture, a hidden component of the hydrologic cycle. Proceedings of the National Academy of Sciences, 115 (11):2664-2669, 2018.

30. Erica L McCormick, David N Dralle, W Jesse Hahm, Alison K Tune, Logan M Schmidt, K Dana Chadwick, and Daniella M Rempe. Widespread woody plant use of water stored in bedrock. Nature, 597(7875):225-229, 2021.

31. Michael L Goulden and Roger $C$ Bales. California forest die-off linked to multi-year deep soil drying in 2012-2015 drought. Nature Geoscience, 12(8):632-637, 2019

32. P Zion Klos, Michael L Goulden, Clifford S Riebe, Christina L Tague, A Toby O'Geen, Brady A Flinchum, Mohammad Safeeq, Martha H Conklin, Stephen C Hart, Asmeret Asefaw Berhe, et al. Subsurface plant-accessible water in mountain ecosystems with a mediterranean climate. Wiley Interdisciplinary Reviews: Water, 5(3):e1277, 2018.

33. W Jesse Hahm, DM Rempe, DN Dralle, TE Dawson, and WE Dietrich. Oak transpiration drawn from the weathered bedrock vadose zone in the summer dry season. Water Resources Research. 56 (11): e2020WR027419, 56(11), 2020.

34. Keirnan JA Fowler, Gemma Coxon, Jim E Freer, Wouter JM Knoben, Murray C Peel, Thorsten Wagener, Andrew W Western, Ross A Woods, and Lu Zhang. Towards more realistic runoff projections by removing limits on simulated soil moisture deficit. Journal of Hydrology, 600: 126505, 2021.

35. Kazuhito Ichii, Weile Wang, Hirofumi Hashimoto, Feihua Yang, Petr Votava, Andrew R Michaelis, and Ramakrishna R Nemani. Refinement of rooting depths using satellite-based evapotranspiration seasonality for ecosystem modeling in california. Agricultural and Forest Meteorology, 149(11):1907-1918, 2009.

36. Felix W Landerer and SC Swenson. Accuracy of scaled grace terrestrial water storage estimates. Water resources research, 48(4), 2012.

37. Lan Wang-Erlandsson, Wim GM Bastiaanssen, Hongkai Gao, Jonas Jägermeyr, Gabriel B Senay, Albert IJM Van Dijk, Juan P Guerschman, Patrick W Keys, Line J Gordon, and Hubert HG Savenije. Global root zone storage capacity from satellite-based evaporation. Hydrology and Earth System Sciences, 20(4):1459-1481, 2016.

38. David N Dralle, W Jesse Hahm, K Dana Chadwick, Erica McCormick, and Daniella M Rempe. Accounting for snow in the estimation of root zone water storage capacity from precipitation and evapotranspiration fluxes. Hydrology and Earth System Sciences, 25(5):2861-2867, 2021.

39. James W Roche, Qin Ma, Joseph Rungee, and Roger C Bales. Evapotranspiration mapping for forest management in california's sierra nevada. Frontiers in Forests and Global Change, 3:69, 2020.

40. J Grindley. Calculated soil moisture deficits in the dry summer of 1959 and forecast dates of first appreciable runoff. Int. Ass. Sci. HydroL, pages 109-20, 1960.

41. Alys C Thomas, John T Reager, James S Famiglietti, and Matthew Rodell. A grace-based water storage deficit approach for hydrological drought characterization. Geophysical Research Letters, 41(5):1537-1545, 2014.

42. A Geruo, Isabella Velicogna, John S Kimball, Jinyang Du, Youngwook Kim, Andreas Colliander, and Eni Njoku. Satellite-observed changes in vegetation sensitivities to surface soil moisture and total water storage variations since the 2011 texas drought. Environmental Research Letters, 12(5):054006, 2017.

43. W Steven Holbrook, Clifford S Riebe, Mehrez Elwaseif, Jorden L. Hayes, Kyle Basler-Reeder, 
Dennis L. Harry, Armen Malazian, Anthony Dosseto, Peter C. Hartsough, and Jan W. Hopmans. Geophysical constraints on deep weathering and water storage potential in the southern sierra critical zone observatory. Earth Surface Processes and Landforms, 39(3):366-380, 2014.

44. Jonathan A Wald, Robert C Graham, and Phillip J Schoeneberger. Distribution and properties of soft weathered bedrock at $\leq 1 \mathrm{~m}$ depth in the contiguous united states. Earth Surface Processes and Landforms, 38(6):614-626, 2013.

45. Ronald Amundson, Arjun Heimsath, Justine Owen, Kyungsoo Yoo, and William E Dietrich. Hillslope soils and vegetation. Geomorphology, 234:122-132, 2015.

46. California Department of Water Resources. Water year 2021: An extreme year, 2021. accessed at https://water.ca.gov/-/media/DWR-Website/Web-Pages/Water-Basics/Drought/ Files/Publications-And-Reports/091521-Water-Year-2021-broch_v2.pdf.

47. Daniel L Swain, Baird Langenbrunner, J David Neelin, and Alex Hall. Increasing precipitation volatility in twenty-first-century california. Nature Climate Change, 8(5):427-433, 2018.

48. Lauren Lowman and Ana Paula Barros. Fire-induced canopy changes alter plant water, energy and carbon relations for coastal plains forests in the southeast us. In AGU Fall Meeting Abstracts, volume 2019, pages B53H-2500, 2019.

49. Gabrielle Boisramé, Sally Thompson, Brandon Collins, and Scott Stephens. Managed wildfire effects on forest resilience and water in the sierra nevada. Ecosystems, 20(4):717-732, 2017.

50. Juli G Pausas and Jon E Keeley. Wildfires as an ecosystem service. Frontiers in Ecology and the Environment, 17(5):289-295, 2019.

51. Heidi J Renninger, Kenneth L Clark, Nicholas Skowronski, and Karina VR Schäfer. Effects of a prescribed fire on water use and photosynthetic capacity of pitch pines. Trees, 27(4): 1115-1127, 2013.

52. W Jesse Hahm, DN Dralle, DM Rempe, AB Bryk, SE Thompson, TE Dawson, and WE Dietrich. Low subsurface water storage capacity relative to annual rainfall decouples mediterranean plant productivity and water use from rainfall variability. Geophysical Research Letters, 46(12): 6544-6553, 2019.

53. W Jesse Hahm, Daniella M Rempe, David N Dralle, Todd E Dawson, Sky M Lovill, Alexander B Bryk, David L Bish, Juergen Schieber, and William E Dietrich. Lithologically controlled subsurface critical zone thickness and water storage capacity determine regional plant community composition. Water Resources Research, 55(4):3028-3055, 2019.

54. Kathleen D Eggemeyer and Susanne Schwinning. Biogeography of woody encroachment: why is mesquite excluded from shallow soils? Ecohydrology: Ecosystems, Land and Water Process Interactions, Ecohydrogeomorphology, 2(1):81-87, 2009.

55. Alison K Tune, Jennifer L Druhan, Jia Wang, Philip C Bennett, and Daniella M Rempe. Carbon dioxide production in bedrock beneath soils substantially contributes to forest carbon cycling. Journal of Geophysical Research: Biogeosciences, 125(12):e2020JG005795, 2020.

56. Elizabeth A Hasenmueller, Xin Gu, Julie N Weitzman, Thomas S Adams, Gary E Stinchcomb, David M Eissenstat, Patrick J Drohan, Susan L Brantley, and Jason P Kaye. Weathering of rock to regolith: The activity of deep roots in bedrock fractures. Geoderma, 300:11-31, 2017.

57. U.S. Geological Survey. National water information system data available on the world wide web (water data for the nation), 2021. accessed December 2021.

58. PRISM Climate Group. Prism rainfall dataset, 2004. accessed at http://prism.oregonstate.edu.

59. Yongqiang Zhang, Dongdong Kong, Rong Gan, Francis HS Chiew, Tim R McVicar, Qiang Zhang, and Yuting Yang. Coupled estimation of $500 \mathrm{~m}$ and 8-day resolution global evapotranspiration and gross primary production in 2002-2017. Remote Sensing of Environment, 222: 165-182, 2019.

60. Rong Gan, Yongqiang Zhang, Hao Shi, Yuting Yang, Derek Eamus, Lei Cheng, Francis HS Chiew, and Qiang Yu. Use of satellite leaf area index estimating evapotranspiration and gross assimilation for australian ecosystems. Ecohydrology, 11(5):e1974, 2018.

61. Yongqiang Zhang, Jorge L Peña-Arancibia, Tim R McVicar, Francis HS Chiew, Jai Vaze, Changming Liu, Xingjie Lu, Hongxing Zheng, Yingping Wang, Yi Y Liu, et al. Multi-decadal trends in global terrestrial evapotranspiration and its components. Scientific reports, 6(1):1-12, 2016.

62. S. Running, Q. Mu, and M. Zhao. Mod16a2 modis/terra net evapotranspiration 8-day 14 global $500 \mathrm{~m}$ sin grid v006 [data set]. nasa eosdis land processes daac, 2017

63. Noel Gorelick, Matt Hancher, Mike Dixon, Simon llyushchenko, David Thau, and Rebecca Moore. Google earth engine: Planetary-scale geospatial analysis for everyone. Remote sensing of Environment, 202:18-27, 2017.

64. MC Anderson, JM Norman, GR Diak, WP Kustas, and JR Mecikalski. A two-source timeintegrated model for estimating surface fluxes using thermal infrared remote sensing. Remote sensing of environment, 60(2):195-216, 1997.

65. Martha C Anderson, John M Norman, John R Mecikalski, Jason A Otkin, and William P Kustas. A climatological study of evapotranspiration and moisture stress across the continental united states based on thermal remote sensing: 1. model formulation. Journal of Geophysical Research: Atmospheres, 112(D10), 2007.

66. Martha C Anderson, John M Norman, John R Mecikalski, Jason A Otkin, and William P Kustas. A climatological study of evapotranspiration and moisture stress across the continental united states based on thermal remote sensing: 2. surface moisture climatology. Journal of Geophysical Research: Atmospheres, 112(D11), 2007.

67. Martha C Anderson, Christopher Hain, Brian Wardlow, Agustin Pimstein, John R Mecikalski, and William $P$ Kustas. Evaluation of drought indices based on thermal remote sensing of evapotranspiration over the continental united states. Journal of Climate, 24(8):2025-2044, 2011.

68. Soil Survey Staff. Gridded national soil survey geographic (gnatsgo) database for the conterminous united states, 2019. https://nrcs.app.box.com/v/soils.

69. Dana A Lapides, W Jesse Hahm, Daniella M Rempe, and David N Dralle. Supplementary code and data for: Root zone storage deficits mediate the production of streamflow from snowmelt, 2021. accessed at https://github.com/lapidesd/CA_missing_freshet.

70. Dana A Lapides, W Jesse Hahm, Daniella M Rempe, and David N Dralle. April 1 swe spatial percentiles using snodas for the contiguous usa, 2021. accessed at https://www.hydroshare. org/resource/4b940b8593a4416e954a47bbbc58c568/. 


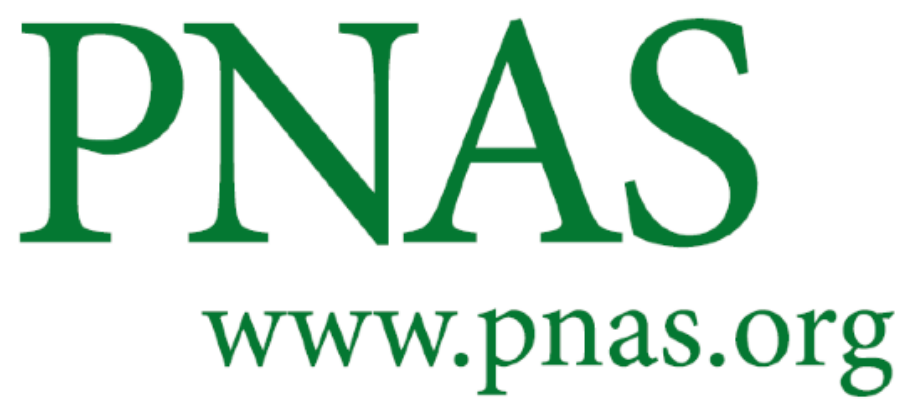

Supplementary Information for

3 Missing snowmelt runoff following drought explained by root-zone storage deficits

4 Dana A Lapides, W Jesse Hahm, Daniella M Rempe, David N Dralle

5 Dana A Lapides.

$6 \quad$ E-mail: dlapides@sfu.ca

7 This PDF file includes:

Supplementary text

Figs. S1 to S6

Tables S1 to S4

SI References 


\section{Supporting Information Text}

\section{Site description and site selection}

California experiences a Mediterranean climate with cool, wet winters and hot, dry summers. In much of California, wet season precipitation arrives as rain, but mountainous regions such as the Sierra Nevada predominantly receive snow. Mediterranean regions generally have highly variable annual precipitation (1) and are subject to rapid switches between drought and flood conditions $(2,3)$. California has a particularly variable climate due to the added influence of complex topography $(4)$. In the past decade, California has experienced extreme drought $(5-7)$ that resulted in extensive wildfires $(8,9)$ and tree mortality (10-12), and periods of extraordinarily high precipitation (13, e.g., winter 2016-2017;) that resulted in widespread flooding (13) and landslides (14).

\begin{tabular}{|c|c|c|c|c|c|c|}
\hline Site & Stream name & Gage location & $\begin{array}{l}\text { Area } \\
{\left[\mathrm{km}^{2}\right]}\end{array}$ & $\begin{array}{l}\text { MAP } \\
{[\mathrm{mm}]}\end{array}$ & Snow percent & Mean Annual Q [mm] \\
\hline \multicolumn{7}{|c|}{ Pristine basins: } \\
\hline 10336780 & Trout Creek & $-119.972,38.9199$ & 95 & 893 & 67 & 315 \\
\hline 10336645 & General Creek & $-120.118,39.0518$ & 19 & 1202 & 58 & 740 \\
\hline 10336660 & Blackwood Creek & $-120.162,39.1074$ & 29 & 1486 & 59 & 1018 \\
\hline 10336676 & Ward Creek & $-120.157,39.1321$ & 25 & 1549 & 61 & 885 \\
\hline 10343500 & Sagehen Creek & $-120.237,39.4315$ & 27 & 976 & 65 & 319 \\
\hline 10308783 & Leviathan Creek & $-119.656,38.7012$ & 11 & 635 & 60 & 50 \\
\hline 11383500 & Deer Creek & $-121.948,40.0140$ & 539 & 1484 & 32 & 499 \\
\hline 11189500 & SF Kern River & $-118.173,35.7374$ & 1373 & 477 & 36 & 72 \\
\hline 11204100 & SF Tule River near Reservation & $-118.813,36.0241$ & 248 & 798 & 25 & 128 \\
\hline 11203580 & $\begin{array}{l}\text { SF Tule River near Cholollo } \\
\text { Camp }\end{array}$ & $-118.654,36.0482$ & 52 & 996 & 44 & 278 \\
\hline 11266500 & Merced River at Pohono Bridge & $-119.666,37.7168$ & 831 & 1213 & 60 & 685 \\
\hline 11264500 & $\begin{array}{l}\text { Merced River at Happy Isles } \\
\text { Bridge }\end{array}$ & $-119.558,37.7315$ & 469 & 1199 & 68 & 673 \\
\hline 10265150 & Hot Creek & $-118.817,37.6688$ & 177 & 814 & 72 & 262 \\
\hline \multicolumn{7}{|c|}{ Basins essential for California water supply: } \\
\hline 11525500 & Trinity River & $-122.804,40.7193$ & 1862 & 1445 & 17 & 405 \\
\hline 11377100 & Sacramento River & $-122.187,40.2885$ & 23051 & 972 & 27 & 426 \\
\hline 11270900 & Merced River & $-120.332,37.5216$ & 2748 & 1032 & 29 & 399 \\
\hline 11289650 & Tuolumne River & $-120.442,37.6663$ & 3983 & 1098 & 37 & 222 \\
\hline 11319500 & $\begin{array}{l}\text { Mokelumne River below Merced } \\
\text { Falls }\end{array}$ & $-120.720,38.3127$ & 1408 & 1265 & 38 & 612 \\
\hline 11335000 & Cosumnes River & $-121.045,38.5002$ & 1388 & 1073 & 13 & 292 \\
\hline
\end{tabular}

Table S1. Catchment attributes for study sites. Streamflow and basic site information are from NWIS (15), and climate information are derived from GAGES-II (16).

To explore drivers of low streamflow in 2021 in California, we examined a set of minimally disturbed, gauged watersheds in the Sierra Nevada (Figure 1c in main text). Sites were selected in the Sierra Nevada that met the following criteria:

1. no upstream dams (16),

2. $>20 \%$ precipitation falls as snow annually on average (16),

3. watershed boundaries were delineated in NHD+ (17),

4. $<5 \%$ developed land cover (18),

5. $<5 \%$ cultivated land cover (18),

6. $<35 \%$ burned area between 1990 and 2020 (19),

7. $<20 \%$ logged area (20),

8. at least 10 years with continuous streamflow from April 1 - September 1 (15),

9. streamflow record includes 2021 (15).

All gages that met these criteria were reviewed manually to ensure hydrographs appear unmodified and snowmelt-dominated. We identified 13 catchments that met the selection criteria (Table S1), spread throughout the Sierra Nevada. The sites encompass a range in size from 11 to $1,373 \mathrm{~km}^{2}$, annual precipitation from 369 to $979 \mathrm{~mm}$, and a mean streamflow from 0.3 to $190 \mathrm{~m}^{3} / \mathrm{s}$. About half of the sites drain to the west, while the remaining sites (primarily those in the Tahoe area) drain to the east. Additionally, six basins essential to California's water supply were also included to demonstrate applicability of the presented methods to larger and more complex basins (bottom of Table S1). 


\section{Model description}

Hahm et al. (21) developed a stochastic hydrological model incorporating root zone storage as a simple 1-d bucket that describes annual runoff dynamics in Mediterranean catchments. Similar to Figure 2 in the main text, the model describes a landscape with thin soil but a substantial weathered bedrock zone that stores plant-accessible water. The entire soil and weathered bedrock zone is treated as a single plant-accessible storage reservoir $S[\mathrm{~L}]$. During the wet season, precipitation $P$ $[\mathrm{L}]$ contributes water to storage, and evapotranspiration $E T[\mathrm{~L}]$ removes water from storage primarily during the dry season. Streamflow is generated only if the subsurface storage reservoir is full.

Hahm et al. (21), however, did not consider the scenario in which deficits were not replenished and could carry over between years. Evidence from field observations of soil and rock moisture and tree mortality $(22,23)$ and from water balance approaches using satellite data products (24-26) shows that root zone storage deficits can grow over multiple years, meaning that the deficit can vary substantially between years in a way that is important for vegetation response. Fowler et al. (27) also recently found that many hydrological models that lack the ability to generate multi-year deficits are unable to simulate streamflow conditions through multi-year droughts in Australia. Changes in subsurface storage (and deficit) give watersheds "memory" of prior precipitation that can persist. Peterson et al. (28) found that more than 8 years after the Millennium Drought in southeastern Australia, many watersheds had not returned to pre-drought conditions. They inferred that enhanced evaporation due to warmer conditions slowed recharge to the subsurface so that deficits generated during the Millennium Drought still were not satisfied. Thus, changes in ET can impact streamflow generation and also provide a feedback that strengthens the importance of subsurface storage deficit on streamflow.

Here, we extend the model presented by Hahm et al. (21) to allow for both multi-year deficit accrual and snow. To allow for multi-year deficit accrual, we explicitly track a timeseries of annual October 1 deficit so that initial water year conditions may vary between years, and to account for snow, we add a snowmelt period following the wet season (during which rain enters storage and snow accumulates), with the April 1 snowpack SWE [L] delivered at a rate of $m$ [L/T]. Hahm et al. (21) assumed that cumulative wet season ET is constant from year to year, an assumption that was meant to reflect the fact that ET is energy-limited during the cold wet season in California. When considering the snowmelt period, though, ET total may not be constant between years since the length of the snowmelt period can vary substantially depending on the snowmelt rate $m[\mathrm{~L} / \mathrm{T}]$ and the size of the snowpack $S W E$. This dynamic can be accounted for in the snowmelt period by considering ET during the melt period and post-snowmelt growing period as energy-determined rates $E T_{s}[\mathrm{~L} / \mathrm{T}]$ and $E T_{\text {summer }}[\mathrm{L} / \mathrm{T}]$ that last for the duration of the melt period and summer respectively. Then, the total warm season $E T_{\text {warm }}=N_{\text {melt }} E T_{s}+N_{\text {warm }}$ dry $E T_{\text {summer }}$ [L], where $N_{\text {melt }}[\mathrm{T}]$ and $N_{\text {warm_dry }}[\mathrm{T}]$ are the lengths of the melt period and post-snowmelt growing season, respectively.

Thus, the extended model includes three seasons with distinct fluxes: a winter wet season, a snowmelt period, and a snowmelt-free growing season:

$$
\begin{aligned}
S_{A p r 1} & =\min \left(S_{\max }, \max \left(0, S_{O c t 1}+P_{w}-E T_{w}\right)\right), \\
S_{A u g 1} & =\min \left(S_{\max }, \max \left(0, S_{A p r 1}+S W E-\left(E T_{s}-P_{s}\right) N_{\text {melt }}\right)\right), \\
S_{O c t 1} & =\max \left(0, S_{A u g 1}-E T_{\text {summer }} N_{\text {warm_dry }}\right),
\end{aligned}
$$

where $S_{A p r 1}[\mathrm{~L}]$ is the root zone storage at the start of the snowmelt period, $S_{A u g 1}[\mathrm{~L}]$ is the root zone storage at the start of the post-snowmelt growing period, and $S_{O c t 1}[\mathrm{~L}]$ is the root zone storage at the start of the winter wet season. $S_{\text {max }}[\mathrm{L}]$ is the size of the root-zone storage, $E T_{w}[\mathrm{~L}]$ is winter ET, and $P_{w}[\mathrm{~L}]$ and $P_{s}[\mathrm{~L} / \mathrm{T}]$ are winter and spring rainfall. Storage is constrained between 0 and $S_{\max }$, so ET cannot occur if storage is empty, and streamflow is generated if storage is full, which can happen during the winter wet season or during the snowmelt period. Equation 1 describes the winter wet season when rain increases storage and ET draws from storage, Equation 2 the melt period when SWE melts into storage and a net ET flux draws from storage, and Equation 3 the post-melt growing season when ET draws from storage. For simplicity, we define a single term $E T_{n e t}=E T_{s}-P_{s}$ that describes the potential net ET during the melt period, and $E T_{\text {summer }}$ can be considered in the same way in regions with significant precipitation during the growing season.

In the present study, we are interested in streamflow produced during the snowmelt period. By using the mass balance from Equations 1-3, streamflow during the snowmelt period is given by:

$$
Q= \begin{cases}\max \left(0, S W E-E T_{n e t} N_{\text {melt }}\right), & \text { if } P_{w}-E T_{w}>D_{\text {Oct } 1} \\ \max \left(0, S W E-E T_{n e t} N_{\text {melt }}-D_{O c t 1}+\left(P_{w}-E T_{w}\right)\right), & \text { otherwise }\end{cases}
$$

where $Q[\mathrm{~L}]$ is total streamflow due to snowmelt, and $D_{\text {Oct } 1}[\mathrm{~L}]$ is the root zone storage deficit $\left(S_{\max }-S_{\text {Oct } 1}\right)$ at the end of the preceding dry season. Both conditions are bounded by 0 since streamflow cannot be negative. A negative value for either condition indicates that water demand from ET exceeds water availability from rain, snowmelt, and storage, so streamflow must be 0 .

In Equation 4, there are at most three terms that can cause the relationship between $S W E$ and $Q$ to be non-unique: (i) the total net ET flux during the melt period $\left(\left(E T_{s}-P_{s}\right) N_{\text {melt }}\right)$, which is impacted indirectly by the melt rate $m$ since $m=S W E / N_{\text {melt }}$, (ii) the root zone storage deficit at the end of the dry season $D_{\text {Oct } 1}$ (referred to as Oct. 1 deficit), which is driven by ET, precipitation, and runoff dynamics during prior years, and (iii) winter recharge $\left(P_{w}-E T_{w}\right)$. Increasing total ET during the snowmelt period $\left(E T_{n e t} N_{\text {melt }}\right)$ reduces streamflow generation. This ET term can be increased by increasing vegetation demand (increased $E T_{n e t}$ ), reducing spring rainfall (increased $E T_{n e t}$ ), or by slowing down the snowmelt rate $m$ (increased length of $N_{\text {melt }}$ for the same SWE). While increasing the October 1 deficit reduces streamflow generation, increasing 
winter recharge $\left(P_{w}-E T_{w}\right)$ can increase streamflow generation. This can be achieved either by increasing $P_{w}$ (decreasing annual snow fraction since SWE remains constant) or decreasing $E T_{w}$ (reducing winter ET), so long as storage is not already being filled up. See Supplemental Information $\mathrm{S} 2$ for a visual demonstration of how each parameter impacts $Q$. Any of these mechanisms could impact performance of a linear regression model for streamflow based only on April 1 SWE.

\section{Subsurface deficit calculations}

To estimate a storage deficit in the subsurface $(D)$, we adapted the method presented by Wang-Erlandsson et al. (25) and updated to account for snow cover by Dralle et al. (29). In this method, root zone storage deficit is calculated as the running difference between fluxes leaving $\left(F_{\text {out }}[\mathrm{L} / \mathrm{T}]\right)$ and entering $\left(F_{\text {in }}[\mathrm{L} / \mathrm{T}]\right)$ the system during a time interval defined by the sampling frequency of remotely sensed products. Generally, $F_{\text {out }}$ is set equal to $E T$, neglecting streamflow, and $F_{\text {in }}$ is set equal to precipitation. Dralle et al. (29) used snow cover data from satellite products to adjust fluxes in snow-dominated regions. Here, since we have access to explicit information on snow through SNODAS (30), we incorporate snow directly into the mass balance approach by defining $F_{\text {in }}$ as

$$
F_{i n}=P_{r}+Q_{m}
$$

where $P_{r}$ is precipitation falling as rain determined as precipitation when SWE does not increase, and $Q_{m}$ is given by decreases in SWE. More precisely,

$$
P_{r, t_{n}}=P_{t_{n}}-\max \left(\mathrm{SWE}_{t_{n}}-\mathrm{SWE}_{t_{n-1}}, 0\right),
$$

where $P_{i}$ is the total precipitation falling in timestep $i$ and $S W E_{i}$ is the SWE at time step $i$ and

$$
Q_{m}=\max \left(\mathrm{SWE}_{t_{n-1}}-\mathrm{SWE}_{t_{n}}, 0\right) .
$$

Following the deficit tracking procedure presented by Wang-Erlandsson et al. (25), we proceed by calculating the difference between $F_{\text {out }}$ and $F_{\text {in }}$ over a time interval from $t_{n}$ to $t_{n+1}$ :

$$
A_{t_{n} \rightarrow t_{n+1}}=\int_{t_{n}}^{t_{n+1}}\left(F_{\text {out }}-F_{\text {in }}\right) d t .
$$

This accumulated difference $\left(A_{t_{n} \rightarrow t_{n+1}}\right)$ is a deficit, so the signs of fluxes are reversed compared to a traditional mass balance. If the accumulated difference is negative, then no deficit has been accrued in the time step. So, a lower bound on root zone storage deficit for each time step is given by the maximum value of zero and the running sum of accumulated differences:

$$
D\left(t_{n+1}\right)=\max \left(0, D\left(t_{n}\right)+A_{t_{n} \rightarrow t_{n+1}}\right)
$$

Runoff is not needed to calculate accurate deficits. Runoff is not included in the storage calculations but is itself a loss term that draws from storage and could theoretically increase root-zone storage deficits. However, water drains out of the root-zone and generates streamflow with a temporal delay that could be weeks to months. Incorporating streamflow into deficit calculations thus should not be accomplished using measured streamflow fluxes but rather using a drainage term, which is not straightforward to monitor. Lack of knowledge of the drainage term is not particularly problematic, however, as the drainage flux should have a minimal impact on deficit growth. Significant drainage occurs only when the deficit is small or zero and is driven by water inputs (snowmelt or precipitation). In general, drainage fluxes are smaller than the water fluxes that generate drainage, and ET is small relative to water inputs, meaning that the net change to the deficit would be negligible. Since the deficit is (or is nearly) zero when drainage occurs, neglecting drainage would not cause the deficit to shrink artificially, and the relative magnitudes of fluxes suggest that the deficit also would not grow with the inclusion of drainage. As a result, neglecting drainage in deficit calculations should not have a significant impact on calculated root-zone storage deficits.

\section{Factors that impact spring streamflow generation}

\begin{tabular}{llllllll} 
Panel & $S_{\max }$ & $\mathrm{ET}_{\text {warm }}$ & $\mathrm{ET}_{w}$ & $\mu$ & $s d$ & snowfrac & $m$ \\
\hline a & 1,000 & $10-300$ & 0 & 400 & 100 & 1 & 10 \\
b & 300 & 800 & 0 & 700 & 150 & 0.7 & $10-50$ \\
c & 1,000 & 350 & 0 & 400 & 100 & 1 & 10 \\
d & 300 & 300 & 0 & 400 & 100 & $0.25-1$ & 10
\end{tabular}

Table S2. Parameter values used to generated each subfigure in Figure S1: $S_{\max }$ is maximum root zone storage; PET is total potential evapotranspiration in the warm season; $E T_{w}$ in the winter; $\mu$ and $s d$ are parameters for the gamma distribution for annual precipitation; snowfrac is the fraction of annual precipitation that falls as snow; and $m$ is the snowmelt rate.

As described in the main text, the relationship between April 1 SWE and spring streamflow is not unique. Within a mass balance framework, there are four factors that can drive lower spring streamflow: (a) more net spring ET (ET-rain), (b) a slower snowmelt rate, (c) a larger root zone storage deficit, or (d) less rainfall. Figure S1 uses the mass balance model to show directly how each of these four factors affects the resulting spring streamflow. For this exercise, we use this total $\mathrm{ET}_{\text {warm }}$ to set an average rate of ET during the warm season that is applied to both the snowmelt period and post-snowmelt growing season. We 


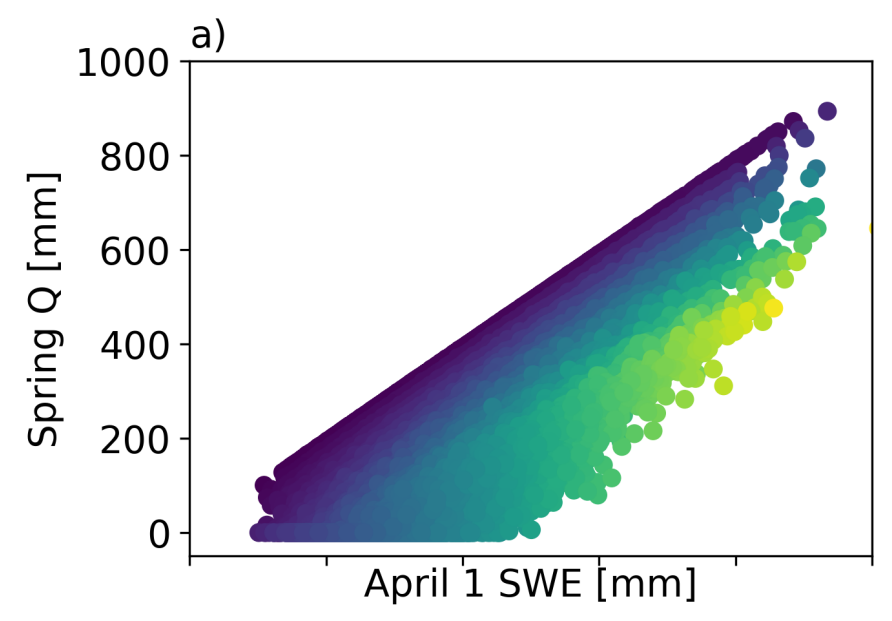

b)
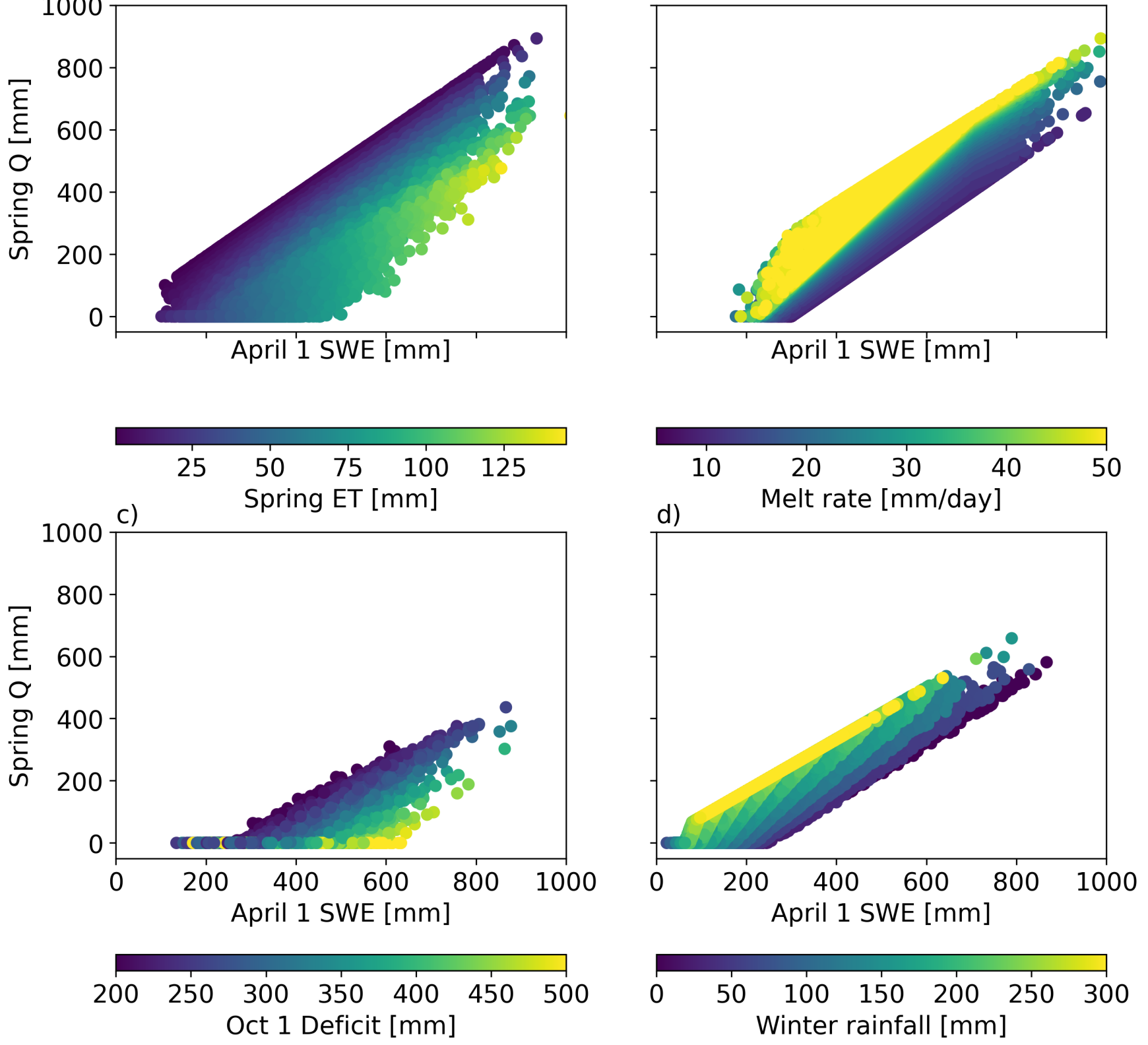

Fig. S1. Differences in (a) spring evapotranspiration (ET), (b) snow melt rate, (c) root zone storage deficit, and (d) winter rainfall can result in different spring streamflow from the same April 1 SWE, as shown by Monte Carlo simulations with annual precipitation P selected from a gamma distribution and April 1 SWE given as a fraction of P. Parameters used to generate this figure are shown in Table S2. Melt rate is calculated assuming a 180 day warm season.

apply Equations 1-3 to track storage through time. Parameters $S_{\text {max }}, E T_{w}$, and $E T_{\text {warm }}=E T_{s} N_{\text {melt }}+E T_{\text {summer }} N_{w a r m \_d r y}$ are the same each year, while $P_{w}, P_{s}, S W E$, and the partitioning of $E T_{\text {warm }}$ between the snowmelt period and the snow-free growing season vary between years. A spinup period of 100 years is used to generate initial conditions. For each year, we select an annual precipitation from a gamma distribution. Since spring rainfall is included in the term $E T_{n e t}$, we do not explicitly include that rainfall in the annual precipitation. Instead, we allow $S W E$ and $P_{w}$ to add to the gamma-selected annual precipitation, with the partition described by a fraction (snow frac). This setup still results in a gamma distribution for annual precipitation since the spring rainfall is constant. Throughout the simulation period, we track storage deficits generated at the end of each growing season, $S W E$, and snowmelt runoff claculated for each year using Equation 4 . Parameters used to generate the figure are in Table $\mathrm{S} 2$.

\section{Exploratory analysis of variables that impact melt period streamflow}

We performed exploratory data analysis to quantify the importance of each variable that appears in Equation 4 for explaining residuals in snowpack-runoff relationships. This analysis was used to select a minimal set of variables that both encompass 

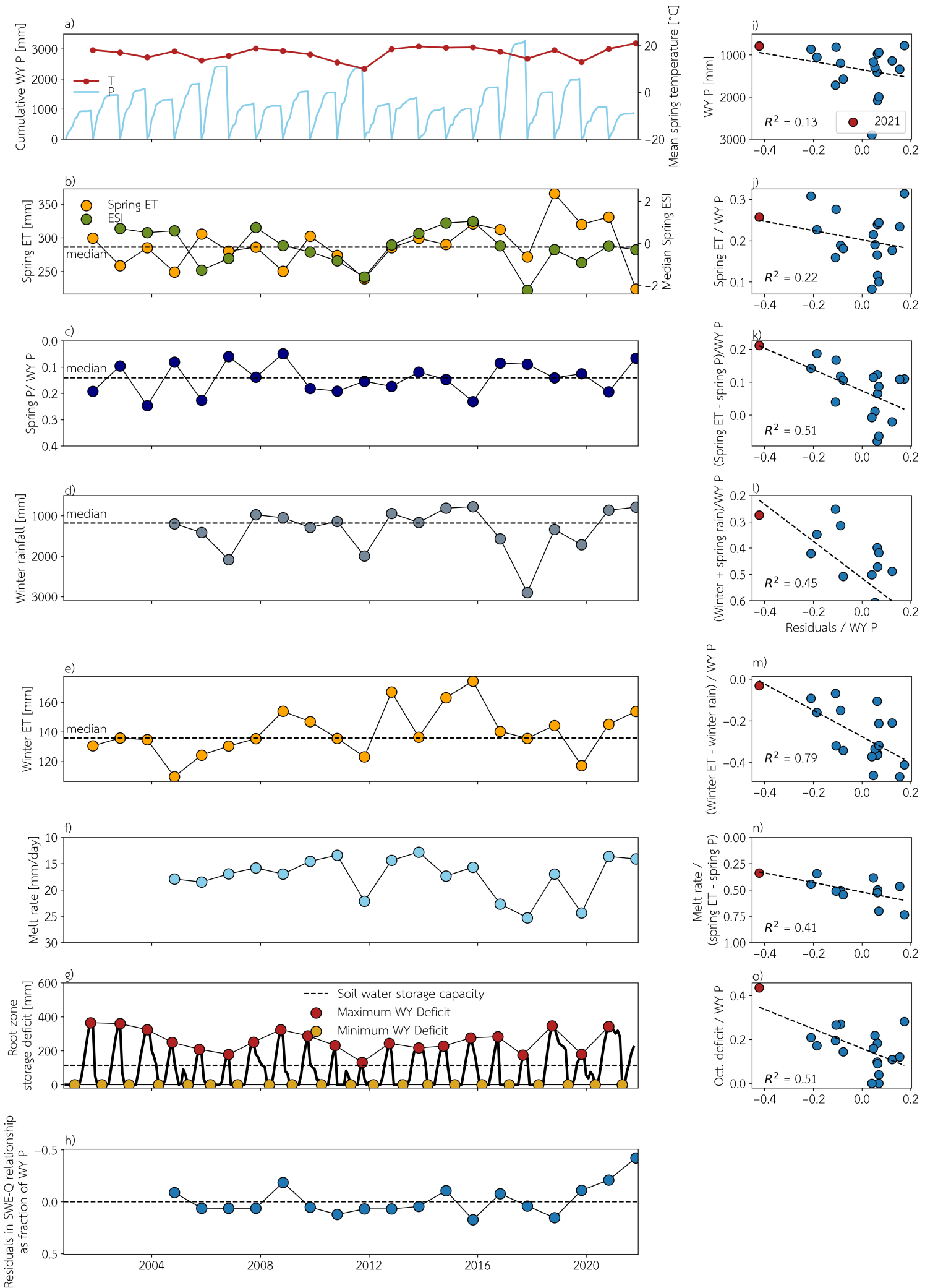

Fig. S2. Water year data for one representative study site (Ward Ck). Spring ET and spring $\mathrm{P}$ are for the months April-July. All panels are oriented so that moving vertically in the panel theoretically results in less spring streamflow. In particular, note that the $y$-axes for panels $c, e, h$, i, and $m$ and the $x$-axis for panels $g$ - $k$ are reversed. As a result, all relationships in panels g-k should appear negative. Red scatter points in panels g-k mark the 2021 water year. 
Table S3. Parameters for the multiple linear regression model to predict spring streamflow. For parameter descriptions, see Table 1 in the main text. Parameter values are shown multiplied by median absolute variable values among (top) top 25 th percentile wettest years and (below) driest 25th percentile of water years and shown in units of $\mathrm{mm}$ for comparison. Values marked by an asterisk indicate that the sign is opposite to the expected sign based on hypothesized mechanisms. Parameter columns are listed in order of decreasing median effect size, so sWE has the largest effect size, and $m / E T_{n e t}$ the smallest across the study sites.

\begin{tabular}{|c|c|c|c|c|c|c|}
\hline Site & SWE & $\frac{P_{w}+P_{s}}{P}$ & $\frac{D_{\text {Oct1 }}}{P}$ & $\frac{E T_{n e t} N_{m e l t}}{P}$ & $\frac{E T_{w}-P_{w}}{P}$ & $\frac{m}{E T_{n e t}}$ \\
\hline \multicolumn{7}{|l|}{ Wet years } \\
\hline 10336780 & 560 & 63 & -15 & $2 *$ & -0 & $-1^{*}$ \\
\hline 10336645 & 929 & 61 & -18 & -2 & -6 & $-10^{*}$ \\
\hline 10336660 & 1195 & 21 & -82 & -2 & -109 & 9 \\
\hline 10336676 & 1268 & 144 & -72 & -5 & -50 & 3 \\
\hline 10343500 & 715 & 37 & -28 & 0 & -41 & $-78^{*}$ \\
\hline 10308783 & 43 & 18 & -19 & -29 & -5 & 53 \\
\hline 11383500 & 118 & 236 & -23 & -6 & -82 & $-2^{*}$ \\
\hline 11189500 & 94 & $-26^{*}$ & -0 & -9 & -9 & 8 \\
\hline 11204100 & 31 & 212 & -12 & -25 & $12^{*}$ & 1 \\
\hline 11203580 & 83 & 160 & -17 & -32 & -42 & 6 \\
\hline 11266500 & 1000 & 59 & -15 & -5 & -36 & 22 \\
\hline 11264500 & 927 & 77 & -13 & -10 & -6 & 8 \\
\hline 10265150 & 56 & 6 & -3 & -2 & -12 & 1 \\
\hline Median & 560 & 61 & -17 & -5 & -12 & 3 \\
\hline \multicolumn{7}{|l|}{ Dry years } \\
\hline 10336780 & 156 & 126 & -66 & $4 *$ & -2 & $-1^{*}$ \\
\hline 10336645 & 144 & 124 & -99 & -27 & -38 & $-5^{*}$ \\
\hline 10336660 & 472 & 21 & -217 & -96 & -89 & 6 \\
\hline 10336676 & 573 & 145 & -199 & -84 & -38 & 2 \\
\hline 10343500 & 240 & 73 & -92 & 1 & -32 & $-29 *$ \\
\hline 10308783 & 2 & 20 & -39 & -64 & -2 & 21 \\
\hline 11383500 & 34 & 215 & -63 & -57 & -57 & $-1^{*}$ \\
\hline 11189500 & 9 & $-33^{*}$ & -1 & -23 & -3 & 5 \\
\hline 11204100 & 1 & 210 & -49 & -87 & $4^{*}$ & 0 \\
\hline 11203580 & 6 & 162 & -62 & -134 & -10 & 2 \\
\hline 11266500 & 197 & 87 & -112 & -29 & -25 & 17 \\
\hline 11264500 & 225 & 118 & -87 & -18 & -2 & 10 \\
\hline 10265150 & 12 & 8 & -61 & -28 & -2 & 1 \\
\hline Median & 144 & 118 & -66 & -29 & -10 & 2 \\
\hline
\end{tabular}

Table S4. Performance of the multiple linear regression model to predict spring streamflow. For parameter descriptions, see Table 1 in the main text. $R^{2}$ values are shown for full model, a model using only April 1 SWE and $D_{\text {Oct } 1} /$ Winter P as variables, and a model only using April 1 SWE. The latter two models can both be run prior to snowmelt.

\begin{tabular}{|c|c|c|c|}
\hline Site & $\begin{array}{l}R^{2} \\
\text { (all params) }\end{array}$ & $\begin{array}{l}R^{2} \\
\left(\mathrm{SWE}, \frac{D_{O c t 1}}{P_{w}}\right)\end{array}$ & $\begin{array}{l}R^{2} \\
\text { (SWE) }\end{array}$ \\
\hline 10336780 & 0.94 & 0.90 & 0.87 \\
\hline 10336645 & 0.93 & 0.90 & 0.88 \\
\hline 10336660 & 0.96 & 0.93 & 0.87 \\
\hline 10336676 & 0.98 & 0.95 & 0.88 \\
\hline 10343500 & 0.98 & 0.79 & 0.73 \\
\hline 10308783 & 0.87 & 0.64 & 0.63 \\
\hline 11383500 & 0.78 & 0.58 & 0.49 \\
\hline 11189500 & 0.87 & 0.75 & 0.83 \\
\hline 11204100 & 0.91 & 0.72 & 0.49 \\
\hline 11203580 & 0.92 & 0.73 & 0.64 \\
\hline 11266500 & 0.96 & 0.92 & 0.91 \\
\hline 11264500 & 0.93 & 0.90 & 0.89 \\
\hline 10265150 & 0.81 & 0.71 & 0.65 \\
\hline Median & 0.93 & 0.85 & 0.83 \\
\hline
\end{tabular}

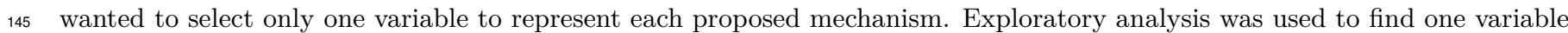
for each mechanism that most strongly correlates with residuals in the SWE-Q model.

Figure S2h shows the time series of residuals in the April 1 SWE-spring Q relationship (referred to hereafter as the SWE-Q relationship). Across all sites, 2021 generally stands out as the largest negative residual as a fraction of WY P (note reversed y-axis). See the data supplement to review residual timeseries for all study sites (31). This finding indicates that less streamflow 
arrived than expected, and the missing streamflow was a substantial portion of the water budget. Based on the parsimonious model described in the main text, we explore four hypotheses to explain why 2021 spring streamflow was lower than expected at the 13 study sites. Results are shown in Figure S2 for Ward Creek (site 10336676), but results across the study sites are qualitatively similar (31, see data supplement;). We selected Ward Creek since it has the highest-performing multiple linear regression model but is otherwise representative of the trends and site characteristics across the study sites.

\section{Hypothesis 1: ET was larger than usual.}

Spring net ET was unusually high. In 2021, spring ET was lower than usual (Figure S2b) despite high spring temperatures (Figure S2a). The Evaporative Stress Index (ESI) data indicate that plants were water-stressed in 2021 (Figure S2b). While ET was not higher than usual, spring ET accounted for a larger fraction of the annual water budget than usual since annual precipitation was very low (Figure S2a). However, spring ET alone does not explain the magnitude of the residual from the SWE-Q relationship in 2021. Spring ET / WY P explains only 22\% of variance in the residuals at Ward Creek (Figure S2j), compared to $13 \%$ explained just by WY P (Figure S2i). Over all sites, the median $R^{2}$ is $22 \%$ for Spring ET / WY P.

Spring rain accounted for a much smaller fraction of annual precipitation than usual in 2021, about half of the median (Figure S2c). As with spring ET in 2021, though, spring P fraction was not outside the range of previously observed values.

Since net spring ET $\left(E T_{n e t}\right)$ is defined as the difference between spring ET and spring rain, the deviations in the individual terms are combined in $E T_{n e t}$. Neither spring ET nor spring rain were outside the range observed in prior years, but $E T_{n e t}$ was unprecedented in 2021 (red scatter point in Figure S2k). ET $T_{n e t}$ both singles out 2021 as a unique year and explains $51 \%$ of variance in the residuals at Ward Creek (Figure S2i). Across all sites, the median $\mathrm{R}^{2}$ value between residuals and $E T_{n e t}$ is 0.38 .

Winter recharge was unusually low. A primary control on winter recharge is winter rainfall $P_{w}$ since snow does not recharge until it melts. Winter rainfall in 2021 was lower than usual, among the lowest winter rainfall years in the study period (Figure S2d) but not outside the range of previously observed values. The other factor controlling winter recharge is winter ET. While spring ET was low in the $2021 \mathrm{WY}$, this was not the case for winter ET, which was higher than normal (Figure S2e). This finding is exaggerated as a fraction of WY $\mathrm{P}$ since 2021 was a dry year (Figure S2m). As with $E T_{n e t},\left(E T_{w}-P_{w}\right) / \mathrm{WY} \mathrm{P}$ singles out 2021 as a particularly extreme year with the highest relative $E T_{w}$ in the study period, an observation that holds for 9 of the 13 study sites, and accounts for $79 \%$ of variance in the residuals at Ward Creek. Across all study sites the median variance explained is $38 \%$, indicating that winter recharge has a predictive power similar to spring net ET.

Hypothesis 2: Winter and spring total rainfall was lower than usual. Both winter rainfall and spring rainfall were lower than usual in the 2021 water year. When combining all winter-spring rain (similar to a snow fraction), rain / WY P explains $45 \%$ of the variance in the residuals in the SWE-Q relationship at Ward Creek (Figure S21). Across all sites, the median is $25 \%$.

Hypothesis 3: Melt rate was unusually slow. By examining Figure S2f, it is clear that the melt rate in 2021 was slower than usual at Ward Creek, among the slowest melt rates observed in the time period 2003-2021, although not outside the previously observed range. A slow melt rate can reduce streamflow by allowing plants to take greater advantage of snowmelt for ET, which means that it is not melt rate alone but its ratio to $E T_{n e t}$ that drives the impact of melt rate on streamflow generation, since $m=S W E / N_{\text {melt }}$ (see Equation 4). In 2021, the ratio $m / E T_{n e t}$ was the smallest observed during the study period, and it explains $41 \%$ of the variance in the residuals at Ward Creek (Figure S2n). At all other study sites, though, $m / E T_{n e t}$ generally explains less than $20 \%$ of variance or even less than $5 \%$ for most sites, with a median of $6 \%$.

Hypothesis 4: Root zone storage deficit was unusually large. Each year, the root zone storage deficit grows during the dry season and shrinks during the wet season (black line in Figure S2g). The maximum deficit each year (red dots, estimated by October 1 deficit for all analyses for simplicity), provides information about how much water was removed from storage during the preceding dry season(s) by ET. Note that the October 1 deficit is always larger than the soil water storage capacity, indicating that plants access water stored in weathered bedrock. The minimum deficit each year (yellow dots) provides information about wet season replenishment of root zone storage. For Ward Creek shown in Figure S2g, the minimum deficit is always 0 , but it can be nonzero and even grow across multiple years at other sites - see the data supplement for study sites that demonstrate deficit carry-over between years (31). In 2021, a large deficit was generated-among the largest during the study period. As with the other hypothesis variables, though, the significance of the 2021 deficit is much clearer when compared to the annual water budget. Figure S2o shows that the deficit as a fraction of the annual precipitation was more than $50 \%$ larger than the largest observed value in previous years. Thus, the deficit strongly identifies 2021 as an outlier, consistent with observations of substantial missing streamflow, and the root zone storage deficit explains $51 \%$ of the variance in residuals in the SWE-Q relationship at Ward Creek. At nearly all study sites, the October 1 deficit in 2021 was the largest or second-largest deficit recorded in the study period (as a fraction of WY P). Some sites have $\mathrm{R}^{2}$ values greater than 0.7 , while others have values less than 0.1 , with a median of 0.32 .

These exploratory analyses motivated the choice of variables included in the multiple linear regression model. The outcomes of the multiple linear regression are summarized in Table S3 for (top) wet years and (bottom) dry years. Performance comparison between different linear regression models is in Table S4. 

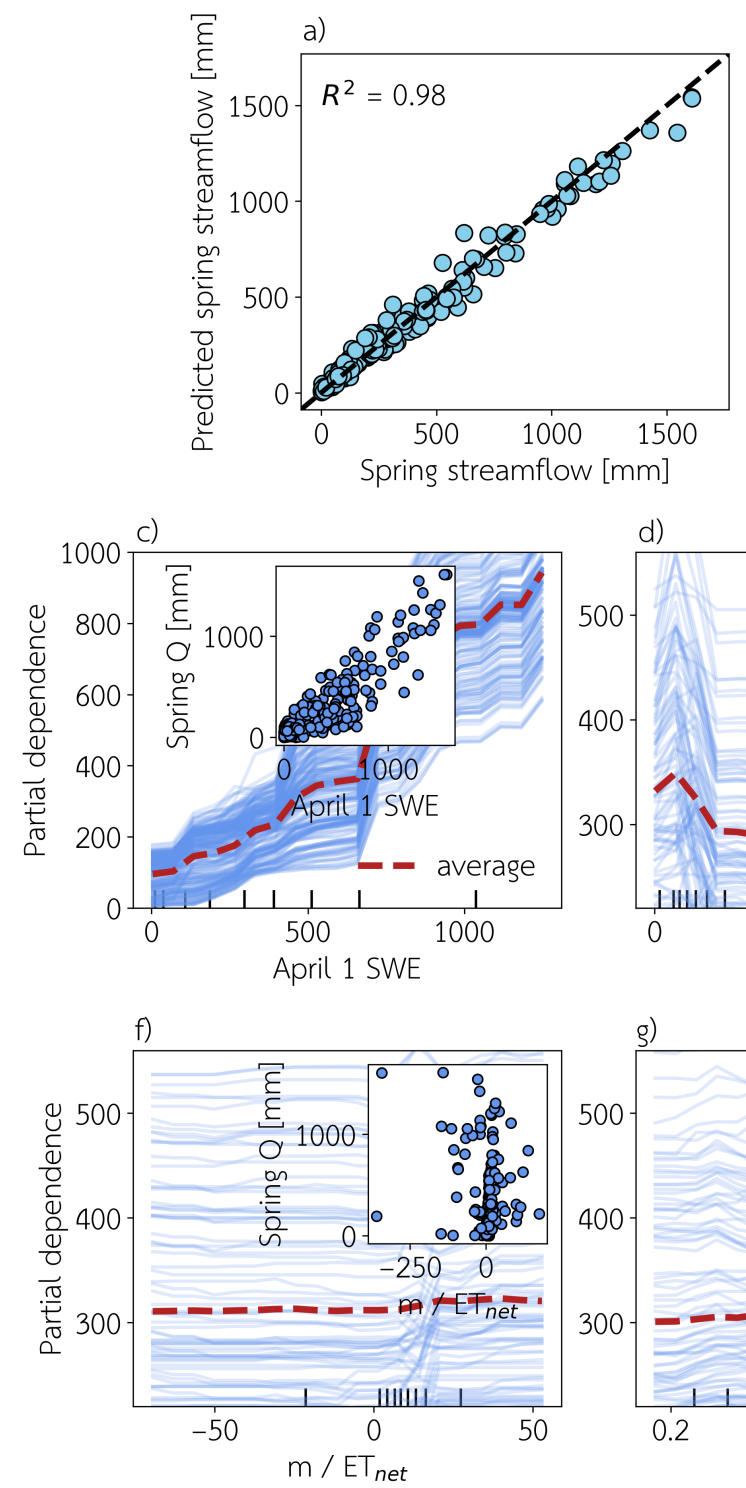

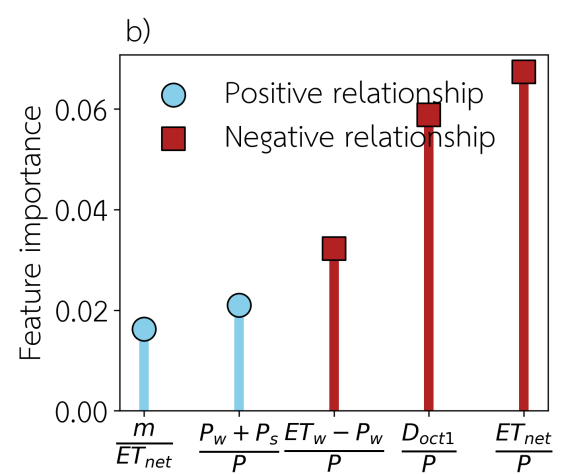

e)
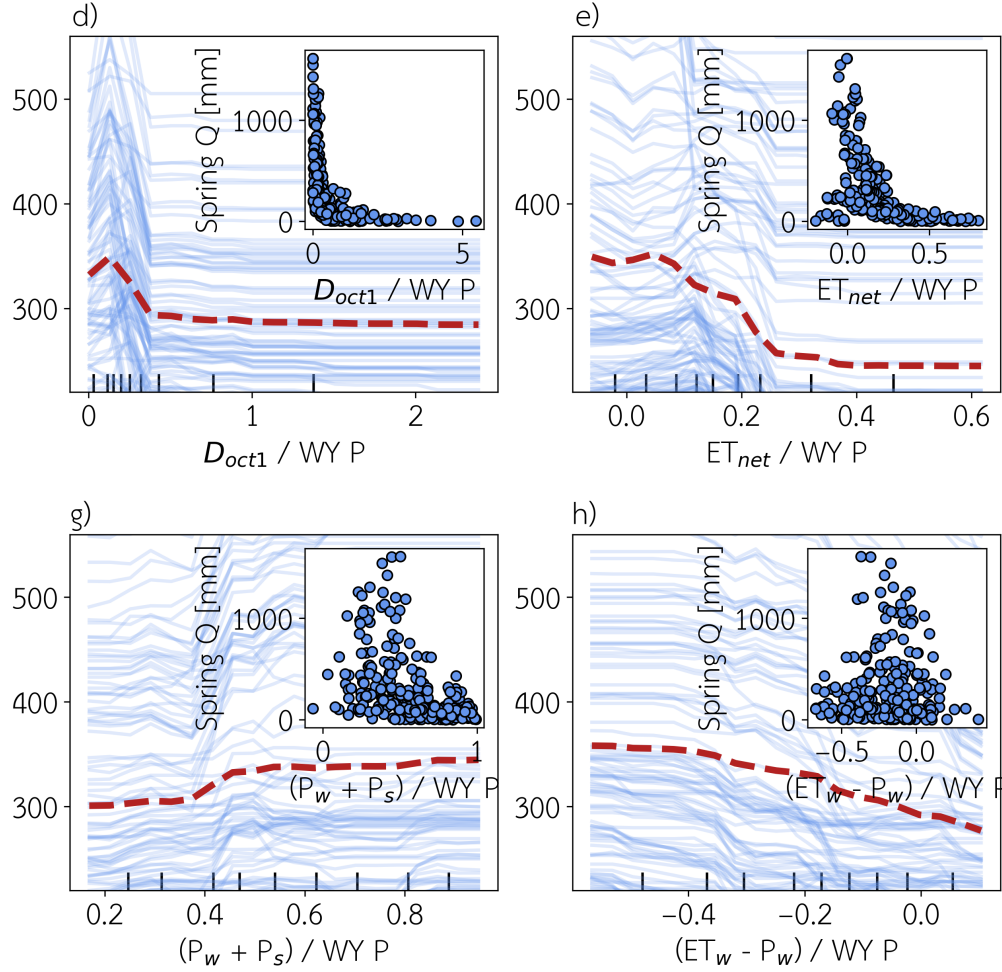

Fig. S3. (a) Performance of random forest model for spring streamflow trained for all study sites. (b) Feature importance for parameters included in random forest model, except for April 1 SWE, which is significantly more important than all other parameters. (c)-(h) are partial dependence plots with the average partial dependence shown as a red dashed line. Panels (d)-(e) are zoomed in, which excludes some of the blue lines but allows for the functional shape of the relationships to be more clearly seen. For comparison, scatter data for the relationship between each parameter and measured spring streamflow is shown as an inset to each subplot.

\section{A random forest model for spring streamflow}

In this study, we developed a multiple linear regression model for each study site to explain spring streamflow production from snowmelt. However, while the model presented in the main text shows linear relationships among all variables for idealized catchments, the relationships between each investigated variable may not be linear for real catchments. To capture more complex relationships among the variables, we also developed a random forest model, using the same set of variables described in Table 1 in the main text. Since random forest models are data-driven and flexible, we chose to train a single random forest model using data from all sites. Performance of the random forest model was exceptional (Figure S3a, $R^{2}=0.98$ ), and feature importance (Figure S3b) supports similar conclusions to the effect size results using the multiple linear regression model. The exact ordering of feature importance is not identical to the ordering implied by the multiple linear regression, but both models support the conclusion that the melt rate does not provide much predictive power, and the deficit provides a substantial amount of predictive power. Partial dependence plots (Figure S3c-h) shows the functional form of the learned relationship between each variable and the output (spring streamflow). These functional forms are nearly monotonic, with small deviations from monotonic behavior likely due to co-variability of variables with parameters not included in the model. In all cases, the general direction of the relationship matches our hypotheses in the main text: (c) higher SWE results in higher streamflow, (d) larger deficit results in smaller streamflow, (e) more spring ET results in less streamflow, (f) a faster melt rate results in more streamflow, $(\mathrm{g})$ more rainfall results in more streamflow, and $(\mathrm{h})$ less winter ET results in more streamflow. Insets show the 
raw data used to train the model. For the most predictive variables, the learned relationship is clearly visible in scatter plots of raw data as well, providing additional confidence in the results.

\section{Including the deficit in a model for snowmelt runoff improves performance on under-predicted years}

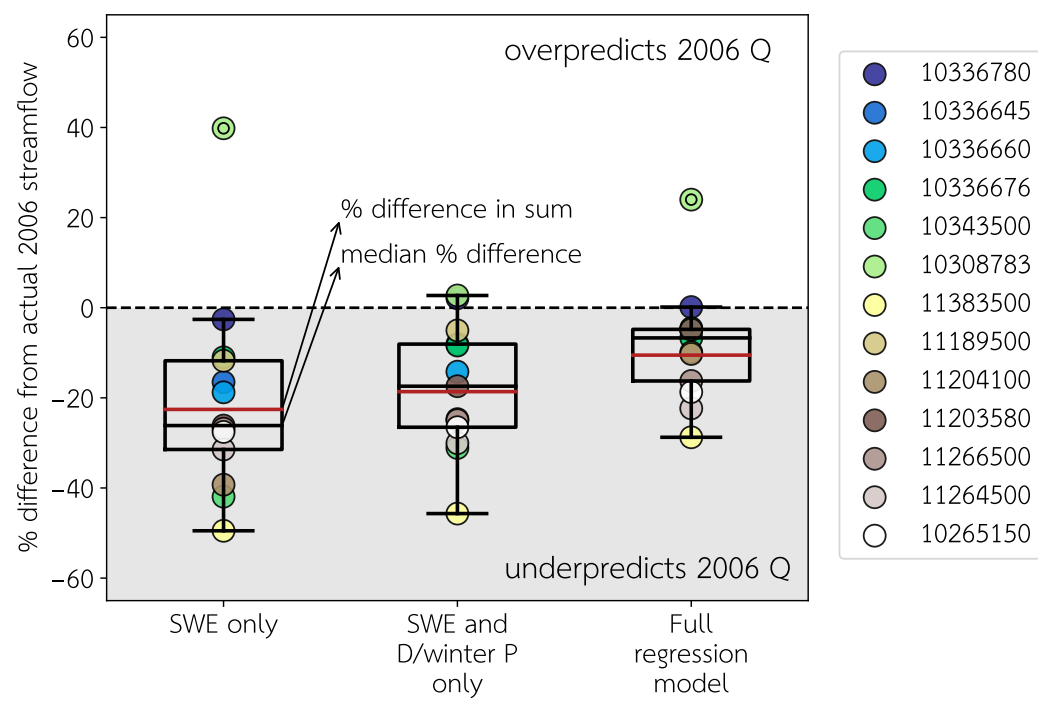

Fig. S4. Performance of regression models at 13 study sites for the year 2021 . A linear regression model using only April 1 SWE underpredicts the total 2006 spring streamflow at all sites by $23 \%$ for total streamflow across all sites (median $26 \%$ ), while the full linear regression model or a model using April 1 SWE and October deficit as a fraction of winter precipitation underpredicts the total by 19 or $11 \%$ (median of 17 or $7 \%$ ), respectively.

In the main text, we explored the importance of the deficit for capturing snowmelt runoff on years with anomalously low runoff. Here, we explore the importance of the deficit for capturing snowmelt runoff on years with anomalously high runoff, such as 2006. Figure S4 demonstrates that including the deficit drastically reduces the extent to which streamflow is underpredicted from a median of $26 \%$ to $17 \%$. While not as striking as the result for 2021 , this difference is still important for management applications and demonstrates that the deficit can improve predictions for all anomalous years, not just overpredicted years.

\section{Including the deficit in a model for snowmelt runoff improves performance on larger, disturbed basins of economic importance}

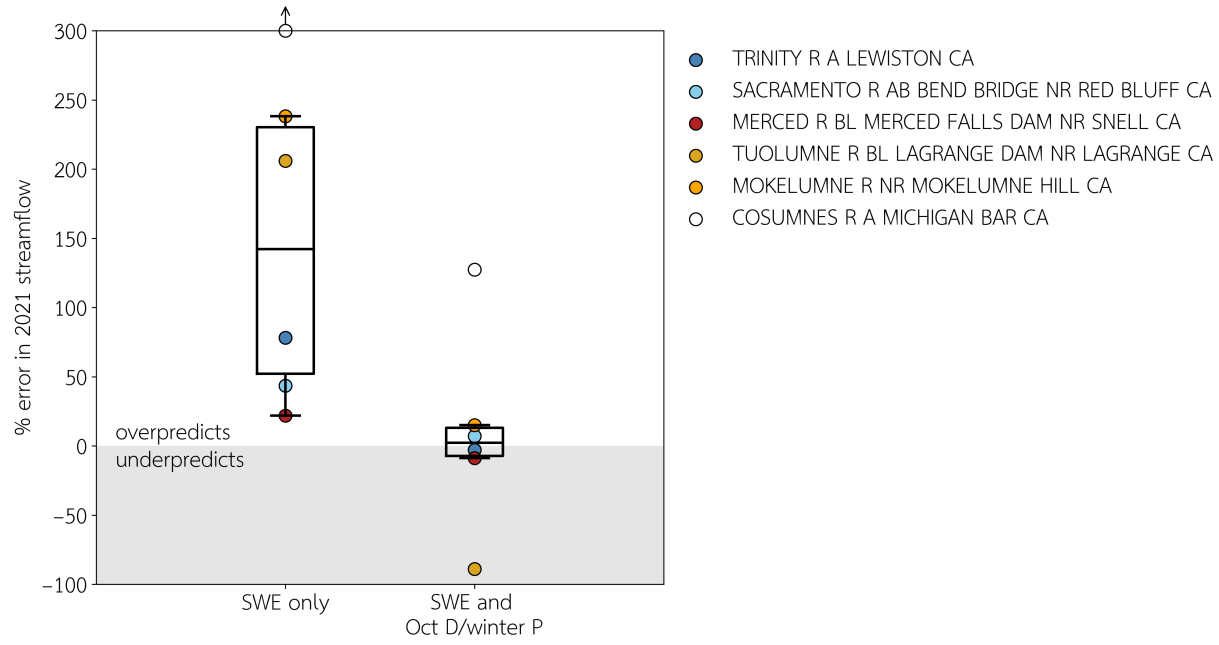

Fig. S5. Comparison of performance of a linear regression model based only on April 1 SWE and one using both April 1 SWE and October 1 Deficit / winter precipitation. Error is reduced from a median of $143 \%$ to $2 \%$.

For this study, we selected a set of minimally disturbed watersheds to test our model. However, the basins where snowmelt runoff predictions matter for water supply are much larger, more complex, and more disturbed than the study sites. To 
a) 25th perc. Apr. 1 SWE

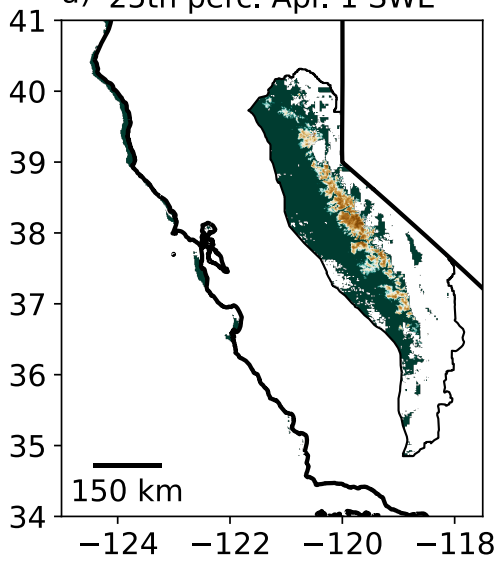

b) Median Apr. 1 SWE

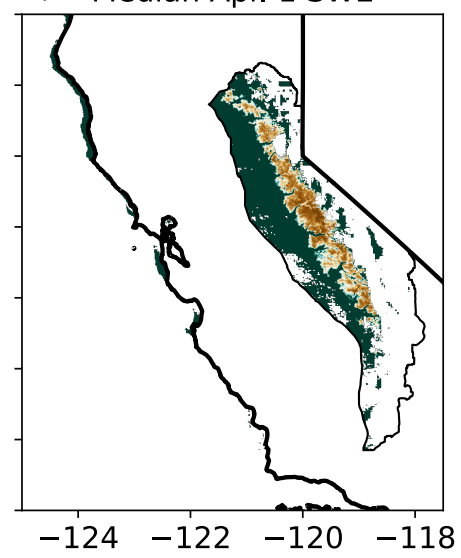

D can be larger than SWE
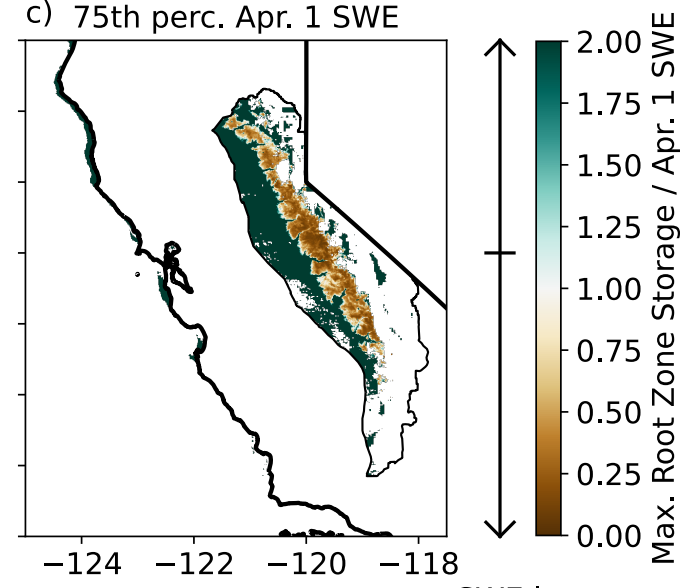

SWE larger

than max. D

Fig. S6. Ratio between maximum root zone storage deficit from 2003-2017 (as calculated by Dralle et al. (29)) and a) 25th percentile, b) median, and c) 75th percentile of April 1 SWE between 2003 and 2021. Results shown only in the Sierra Nevada. White space is missing data. In greener regions, subsurface processes are more likely to cause a linear model for spring streamflow based on April 1 SWE to over-predict streamflow. In browner regions, subsurface processes are likely to have less impact on model performance. Sierra boundary polygon from Conservation Biology Institute (32).

The root zone storage deficit is likely to be important anywhere in the Sierra Nevada where deficits can be substantial relative to snowmelt inputs, meaning that the potential importance of the root zone storage deficit for impacting streamflow generation extends beyond the study sites to much of the mountainous regions in California. The maximum observed deficit from 2003-2017 (29) is a significant fraction of or much larger than the 25th percentile April 1 SWE from 2003-2021 across nearly all of the mountainous regions of California (Figure S6a). Even comparing the maximum deficit to (b) median April 1 SWE or (c) the 75th percentile of April 1 SWE, the deficit can be a substantial part of the water budget. As a result, adding a deficit term to an empirical model for spring streamflow is likely to be important across the Sierra Nevada.

\section{References}

1. Baird Langenbrunner, J David Neelin, Benjamin R Lintner, and Bruce T Anderson. Patterns of precipitation change and climatological uncertainty among cmip5 models, with a focus on the midlatitude pacific storm track. Journal of Climate, 28(19):7857-7872, 2015.

2. Daniel E Horton, Nathaniel C Johnson, Deepti Singh, Daniel L Swain, Bala Rajaratnam, and Noah S Diffenbaugh. Contribution of changes in atmospheric circulation patterns to extreme temperature trends. Nature, 522(7557):465-469, 2015.

3. Michael D Dettinger, Fred Martin Ralph, Tapash Das, Paul J Neiman, and Daniel R Cayan. Atmospheric rivers, floods and the water resources of california. Water, 3(2):445-478, 2011.

4. Daniel L Swain, Baird Langenbrunner, J David Neelin, and Alex Hall. Increasing precipitation volatility in twenty-firstcentury california. Nature Climate Change, 8(5):427-433, 2018.

5. Daniel Griffin and Kevin J Anchukaitis. How unusual is the 2012-2014 california drought? Geophysical Research Letters, 41(24):9017-9023, 2014.

6. Daniel L Swain, Daniel E Horton, Deepti Singh, and Noah S Diffenbaugh. Trends in atmospheric patterns conducive to seasonal precipitation and temperature extremes in california. Science Advances, 2(4):e1501344, 2016.

7. Scott M Robeson. Revisiting the recent california drought as an extreme value. Geophysical Research Letters, 42(16): 6771-6779, 2015.

8. Scott L Stephens, Brandon M Collins, Christopher J Fettig, Mark A Finney, Chad M Hoffman, Eric E Knapp, Malcolm P North, Hugh Safford, and Rebecca B Wayman. Drought, tree mortality, and wildfire in forests adapted to frequent fire. BioScience, 68(2):77-88, 2018. 
9. Noah S Diffenbaugh, Daniel L Swain, and Danielle Touma. Anthropogenic warming has increased drought risk in california. Proceedings of the National Academy of Sciences, 112(13):3931-3936, 2015.

10. Christopher J Fettig, Leif A Mortenson, Beverly M Bulaon, and Patra B Foulk. Tree mortality following drought in the central and southern sierra nevada, california, us. Forest Ecology and Management, 432:164-178, 2019.

11. Alejandro Guarín and Alan H Taylor. Drought triggered tree mortality in mixed conifer forests in yosemite national park, california, usa. Forest ecology and management, 218(1-3):229-244, 2005.

12. Sarah Byer and Yufang Jin. Detecting drought-induced tree mortality in sierra nevada forests with time series of satellite data. Remote Sensing, 9(9):929, 2017.

13. S-Y Simon Wang, Jin-Ho Yoon, Emily Becker, and Robert Gillies. California from drought to deluge. Nature Climate Change, 7(7):465-468, 2017.

14. Alexander L Handwerger, Eric J Fielding, Mong-Han Huang, Georgina L Bennett, Cunren Liang, and William H Schulz. Widespread initiation, reactivation, and acceleration of landslides in the northern california coast ranges due to extreme rainfall. Journal of Geophysical Research: Earth Surface, 124(7):1782-1797, 2019.

15. U.S. Geological Survey. National water information system data available on the world wide web (water data for the nation), 2021. accessed December 2021.

16. JA Falcone. Us geological survey gages-ii time series data from consistent sources of land use, water use, agriculture, timber activities, dam removals, and other historical anthropogenic influences: Us geological survey data release. In $U S$ Geological Survey Data Release. 2017.

17. ME Wieczorek. USGS Streamgage NHDPlus Version 1 Basins 2011, 2011.

18. Collin Homer, Jon Dewitz, Limin Yang, Suming Jin, Patrick Danielson, George Xian, John Coulston, Nathaniel Herold, James Wickham, and Kevin Megown. Completion of the 2011 national land cover database for the conterminous united states-representing a decade of land cover change information. Photogrammetric Engineering $\&$ Remote Sensing, 81(5): 345-354, 2015.

19. State of California and the Department of Forestry and Fire Protection. Fire perimeters through $2020,2021$.

20. CAL FIRE. Timber harvest plans (THPs) - CAL FIRE [ds816], 2019.

21. W Jesse Hahm, DN Dralle, DM Rempe, AB Bryk, SE Thompson, TE Dawson, and WE Dietrich. Low subsurface water storage capacity relative to annual rainfall decouples mediterranean plant productivity and water use from rainfall variability. Geophysical Research Letters, 46(12):6544-6553, 2019.

22. Michael L Goulden and Roger C Bales. California forest die-off linked to multi-year deep soil drying in 2012-2015 drought. Nature Geoscience, 12(8):632-637, 2019.

23. W Jesse Hahm, David N Dralle, Maryn Sanders, Alexander B Bryk, Kristen Elizabeth Fauria, Mong-Han Huang, Berit Hudson-Rasmussen, Mariel D Nelson, Michelle A Pedrazas, Logan Marcos Schmidt, et al. Bedrock vadose zone storage dynamics under extreme drought: consequences for plant water availability, recharge, and runoff. ESSOAR Pre-Print (https://www.essoar.org/doi/abs/10.1002/essoar.10509661.2), 2021.

24. Erica L McCormick, David N Dralle, W Jesse Hahm, Alison K Tune, Logan M Schmidt, K Dana Chadwick, and Daniella M Rempe. Widespread woody plant use of water stored in bedrock. Nature, 597(7875):225-229, 2021.

25. Lan Wang-Erlandsson, Wim GM Bastiaanssen, Hongkai Gao, Jonas Jägermeyr, Gabriel B Senay, Albert IJM Van Dijk, Juan P Guerschman, Patrick W Keys, Line J Gordon, and Hubert HG Savenije. Global root zone storage capacity from satellite-based evaporation. Hydrology and Earth System Sciences, 20(4):1459-1481, 2016.

26. Guotao Cui, Qin Ma, and Roger Bales. Assessing multi-year-drought vulnerability in dense mediterranean-climate forests using water-balance-based indicators. Journal of Hydrology, page 127431, 2022.

27. Keirnan Fowler, Wouter Knoben, Murray Peel, Tim Peterson, Dongryeol Ryu, Margarita Saft, Ki-Weon Seo, and Andrew Western. Many commonly used rainfall-runoff models lack long, slow dynamics: Implications for runoff projections. Water Resources Research, 56(5):e2019WR025286, 2020.

28. Tim J Peterson, M Saft, MC Peel, and A John. Watersheds may not recover from drought. Science, 372(6543):745-749, 2021.

29. David N Dralle, W Jesse Hahm, K Dana Chadwick, Erica McCormick, and Daniella M Rempe. Accounting for snow in the estimation of root zone water storage capacity from precipitation and evapotranspiration fluxes. Hydrology and Earth System Sciences, 25(5):2861-2867, 2021.

30. National Operational Hydrologic Remote Sensing Center. Snow data assimilation system (snodas) data products at nsidc, version $1,2000$.

31. Dana A Lapides, W Jesse Hahm, Daniella M Rempe, and David N Dralle. Supplementary code and data for: Root zone storage deficits mediate the production of streamflow from snowmelt, 2021. accessed at https://github.com/lapidesd/CA missing_freshet.

32. Conservation Biology Institute. Bioregions of California (INACC Regions) , 2011. URL https://databasin.org/datasets/ 0eabf6b3d0b5401d86f472e5297af1ee/. 